\title{
Feedback Control of Flow Separation Using Plasma Actuator and FBG Sensor
}

\author{
Takehiko Segawa, ${ }^{1}$ Daiki Suzuki, ${ }^{1,2}$ Takayasu Fujino, ${ }^{3}$ \\ Timothy Jukes, ${ }^{4}$ and Takayuki Matsunuma ${ }^{1}$ \\ ${ }^{1}$ Research Institute for Energy Conservation, National Institute of Advanced Industrial Science and Technology (AIST), \\ 1-2-1 Namiki, Tsukuba, Ibaraki 305-8564, Japan \\ ${ }^{2}$ Graduate School of Engineering, Information and Systems, University of Tsukuba, 1-1-1 Tennodai, Tsukuba, Ibaraki 305-8577, Japan \\ ${ }^{3}$ Faculty of Engineering, Information and Systems, University of Tsukuba, 1-1-1 Tennodai, Tsukuba, Ibaraki 305-8577, Japan \\ ${ }^{4}$ Department of Engineering, University of Nottingham, University Park, Nottingham NG7 2RD, UK \\ Correspondence should be addressed to Takehiko Segawa; t-segawa@aist.go.jp
}

Received 9 May 2016; Accepted 16 November 2016

Academic Editor: Christopher J. Damaren

Copyright ( 2016 Takehiko Segawa et al. This is an open access article distributed under the Creative Commons Attribution License, which permits unrestricted use, distribution, and reproduction in any medium, provided the original work is properly cited.

A feedback control system for mitigating flow separation was developed by using a string-type dielectric-barrier-discharge (DBD) plasma actuator and a fiber Bragg grating (FBG) sensor. Tangential jets were induced from the string-type DBD plasma actuator, which was located at 5\% chord from the leading edge of an NACA0024 airfoil. The FBG sensor was attached to the interior surface near the root of the cantilever beam modeled on the pressure surface of the airfoil. The strain at the cantilever root was reflected in the form of Bragg wavelengths $\left(\lambda_{B}\right)$ detected by the FBG sensor when the cantilever tip was vibrated by the flow near the trailing edge of the airfoil. It was found that calculating running standard deviations in the Bragg wavelength $\left(\lambda_{B}^{\prime}\right)$ detected by the sensor was valuable for judging flow separation in real time. The feedback control of flow separation on the NACA0024 airfoil was successfully demonstrated by setting $\lambda_{B}^{\prime}=0.0028$ with periodic flow separations generated in a wind tunnel by oscillating a side wall of the test section with frequency $f_{w}=0.42 \mathrm{~Hz}$. It was confirmed that the appearance probability of flow separation tends to decrease with a decrease in the duration for calculating $\lambda_{B}^{\prime}$ and with an increase in the duration of jet injection.

\section{Introduction}

Various studies have been conducted on the flows induced by dielectric-barrier-discharge (DBD) plasma actuators, since the basic structures and possibilities as a flow control device were shown by Roth et al. [1] and Corke et al. [2]. Conventional DBD plasma actuators (named "sheet-type" DBD plasma actuators in this study) consist of a dielectric layer and exposed and encapsulated electrodes. By applying high voltages at radio frequencies between the electrodes, DBD plasma is formed near the edge of the exposed electrode, and then a tangential jet with a strong horizontal velocity component is induced in the vicinity of the surface. The resultant tangential jet is one-directional, irrespective of changes in the polarity of the applied voltage, when the exposed and encapsulated electrodes are arranged asymmetrically in the $x-y$ cross section, as shown in Figures 1(a) and 1(b). Various studies have been conducted, not only to explain the phenomenon based on the experimental and numerical approaches reported by Shyy et al. [3], Roy and Gaitonde [4], Boeuf and Pitchford [5], Forte et al. [6], Moreau [7], Corke et al. [8], and Nishida et al. [9] but also to show the potential for achieving flow separation control and drag reduction through the use of DBD plasma actuators, as shown by Post and Corke [10], Labergue et al. [11], Asada et al. [12], Segawa et al. [13], Choi et al. [14], Walker and Segawa [15], and Jukes et al. [16]. In addition, pulse modulation in DBD plasma actuators, wherein tangential jets are intermittently induced, is remarkable not only for achieving lift enhancement in a variety of airfoils, but also for reducing power consumption. Recent CFD studies using the $\mathrm{K}$ computer have tended to reveal a flow separation control mechanism involving pulse modulation, as described in Sato et al. [17]. Control of flow separation on airfoils and rotor 


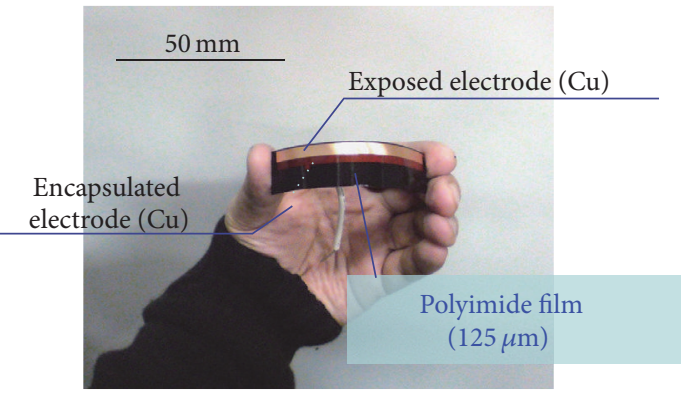

(a)

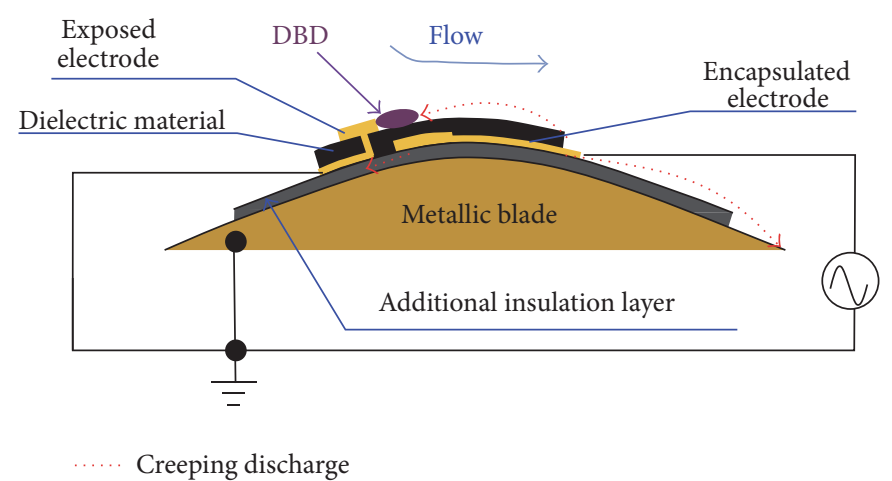

(b)

FIGURE 1: Conventional sheet-type DBD plasma actuator. (a) Picture of sheet-type DBD plasma actuator; (b) an illustration of technical problems for use of sheet-type DBD plasma actuator in actual situations.

blades is an important technological consideration for fluid machinery such as aircraft and wind turbines. In addition to the benefits provided by pulse modulation, the detection of flow separation in real time is effective for minimizing the operation time of DBD plasma actuators. The fiber Bragg grating (FBG) flow sensor is a promising device for detecting flow separation, as described in [18-20], and integrates well with DBD plasma actuators because it is an optical sensor immune to electromagnetic interference.

The application of flow control technologies will expand if DBD plasma actuators can be attached to or embedded in the metallic and three-dimensional surfaces characteristic of actual fluid machinery. Thus far, most research groups have utilized conventional sheet-type DBD plasma actuators as proposed by Roth et al. [1]. However, numerous technical problems must be solved in order to attach DBD plasma actuators to the metallic and three-dimensional surfaces encountered in actual situations, as illustrated in Figure 1(b). From a health and safety perspective, it is inadvisable to use exposed high voltage electrodes on an aerodynamic surface. Conversely, if the high voltage is applied to an encapsulated electrode and the exposed electrode is grounded instead, additional insulation must be inserted in order to use the actuators on metallic structures. Turbomachinery in the field is exposed to rain, moist air, and dust that includes conductive particles, so that additional care must be taken to avoid discharges around insulation areas. In addition, extra insulation causes modifications to the surface shape, adds structural weight, and complicates maintenance.

In order to solve the problems connected with sheet-type DBD plasma actuators, effective active flow control stringtype DBD plasma actuators (as illustrated in Figure 2) were developed, as reported in our previous study [19]. These consist of metallic wires coated with insulating materials, instead of a dielectric sheet and encapsulated electrode, although additional grounded electrodes (exposed electrodes) such as $\mathrm{Cu}$ tapes are necessary when the surfaces to which the wires are attached are composed of insulating materials. In the case of conductive surfaces, the surface itself is chosen as the exposed electrode and connected to ground. As the metallic wires are already coated with insulating materials, they are sufficiently safe for the application of high voltages, although both free ends should be covered to prevent a short circuit. If elastic materials such as silicone resins are chosen as wire insulation, it is possible to put wires on two or threedimensional surfaces. String-type DBD plasma actuators also possess the advantage, in comparison with the sheet-type variety, of being easy to replace in the case of partial damage to the dielectric coating. The flow patterns induced by stringtype DBD plasma actuators vary according to the location of and distance between the metallic wire coated with insulating material and the exposed electrode.

Although string-type DBD plasma actuators and the FBG flow sensor are promising devices for industrial applications, it is necessary to assess their potential in flow conditions similar to those in which fluid machinery is typically operated. In this study, feedback control of transient flow separation, using string-type DBD plasma actuators and an FBG flow sensor, was tested under fluctuating flow conditions, as a preliminary experiment in preparation for use in actual fluid machinery.

\section{Experimental Setup}

A series of experiments was conducted in an opencircuit blow-down wind tunnel with transparent test section $(200 \mathrm{~mm} \times 200 \mathrm{~mm} \times 600 \mathrm{~mm})$, as shown in Figure 3. The mean stream velocity $\left(U_{\infty}\right)$ was varied up to $U_{\infty}=20 \mathrm{~m} / \mathrm{s}$. The leading edge of the NACA0024 airfoil was located $370 \mathrm{~mm}$ downstream from the entrance of the test section and at the tunnel midheight. A NACA0024 airfoil (chord length: $c=80 \mathrm{~mm}$; span width: $s=100 \mathrm{~mm}$ ), composed of ABS plastic and modeled using 3D rapid prototyping (Figure 4), was used to demonstrate feedback control of flow separation. As described in "Introduction," the string-type DBD plasma actuators are possible to attach on metals in principle (see Figure 2), and we are planning to install them in practical fluid machinery which consists of metallic parts, in our future works. In this research, however, it was difficult to construct a NACA0024 airfoil with three-dimensional structure such as cantilever and output shaft made of metals from reasons of technical problems and cost for modeling by the use of a $3 \mathrm{D}$ rapid prototyping machinery. As a result, insulative ABS 


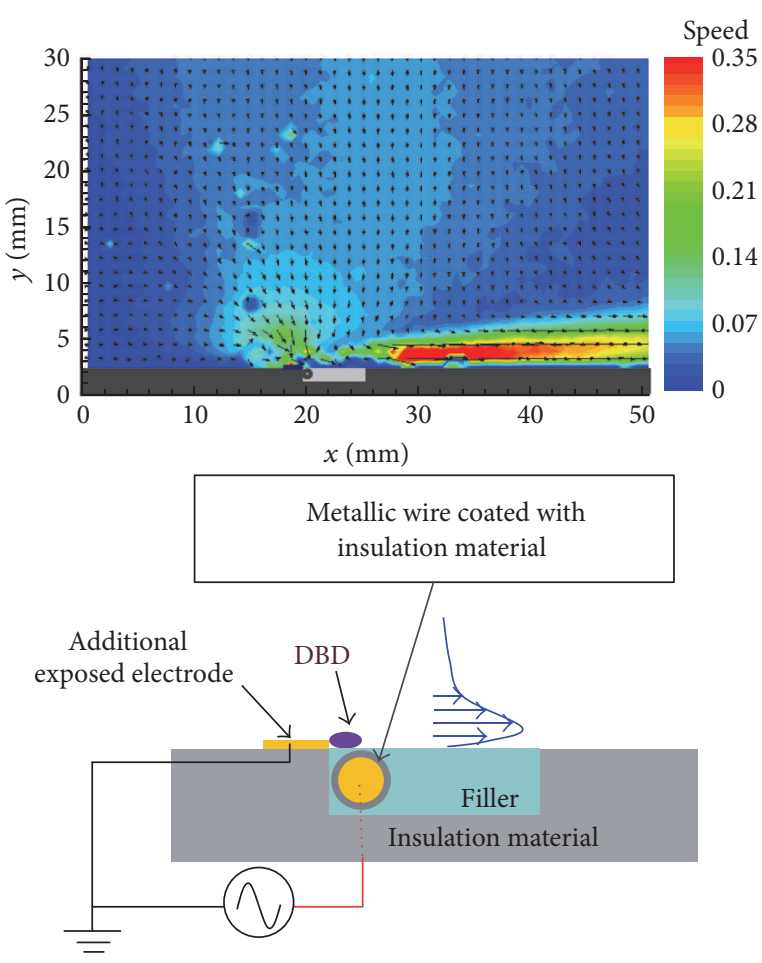

(a)
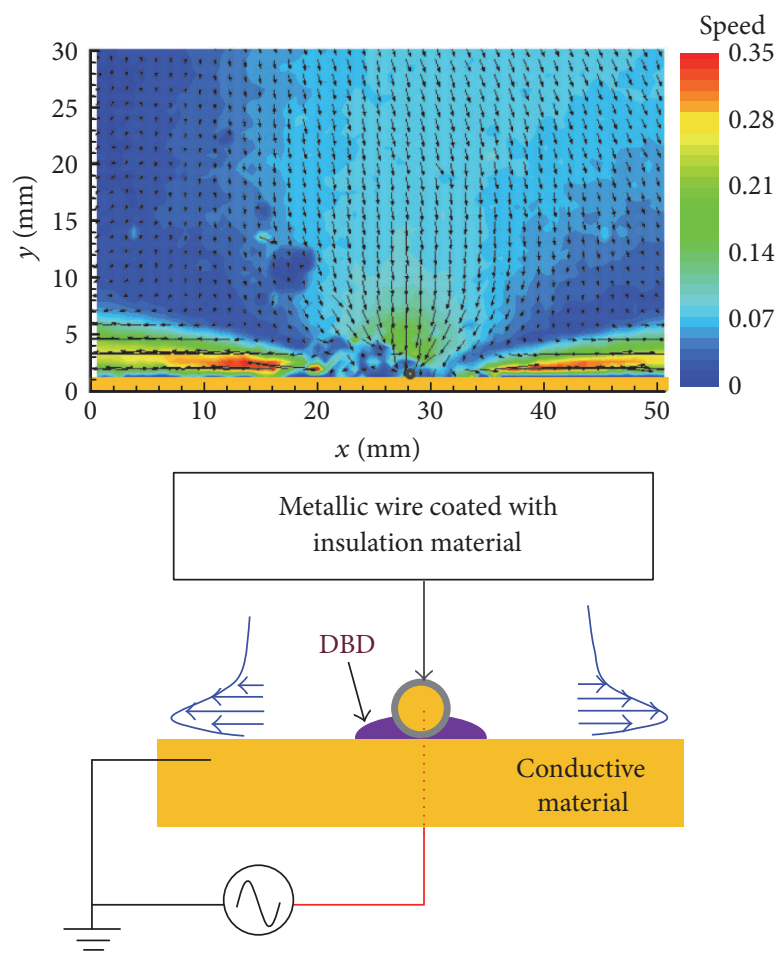

(b)

Figure 2: Basic structures and velocity distributions of string-type DBD plasma actuator designed by Segawa et al. [19]. (a) One-directional tangential jet is induced by embedding a metallic wire coated with insulation materials in insulation material. (b) The surface itself can be chosen as the exposed electrode when the wire is attached on surface of conductive material.

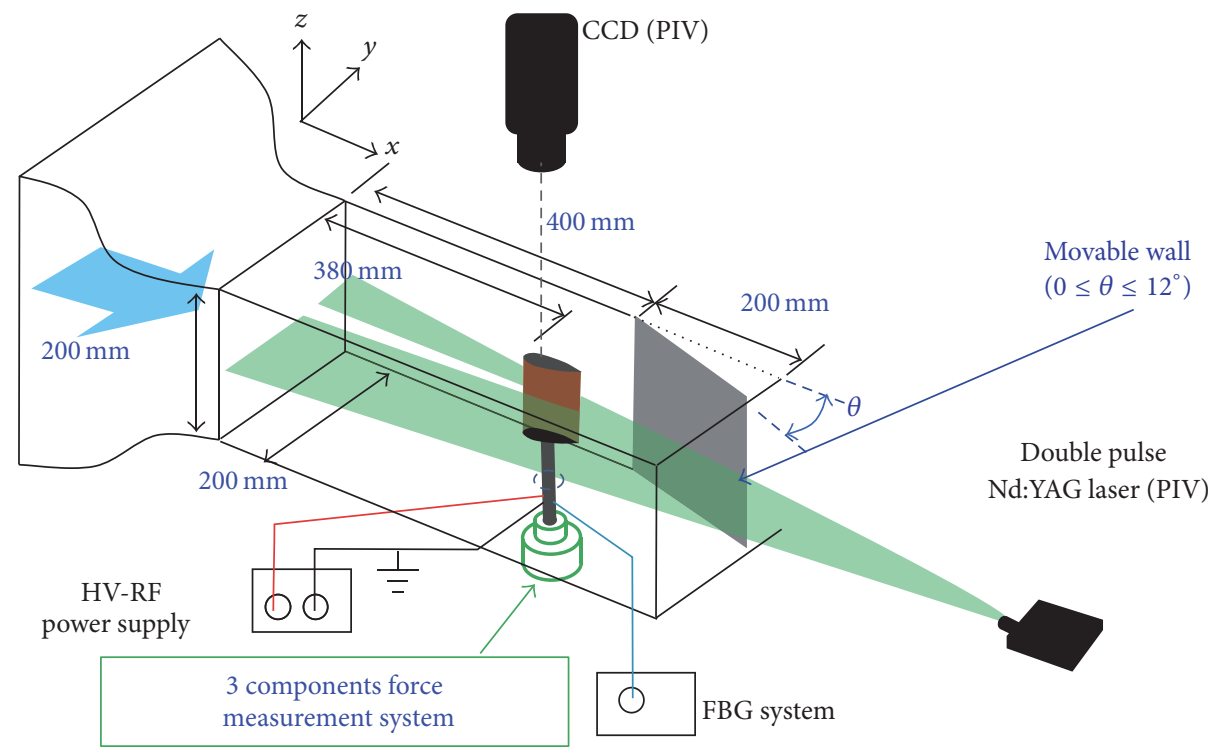

FIgure 3: Schematic illustration of experimental setup. The side wall of the test section near the airfoil suction surface is hinged at $400 \mathrm{~mm}$ downstream of the entrance and can be pivoted over a range of $0^{\circ} \leq \theta \leq 16^{\circ}$.

plastic was chosen as the material of the airfoil. On the other hand, tangential jets can be induced regardless of the material of the airfoil. Therefore, it is considered that control effects of flow separation will be similar even when airfoils made of metals are used. Since flow separation is dependent on the airfoil angles of attack $(\alpha)$ under steady-state conditions, the airfoil was fixed at $\alpha=12^{\circ}$ in this experiment, and the flow was artificially separated by pivoting the test section wall downstream of the airfoil. In this way, wall oscillation downstream of the airfoil was used to demonstrate feedback 


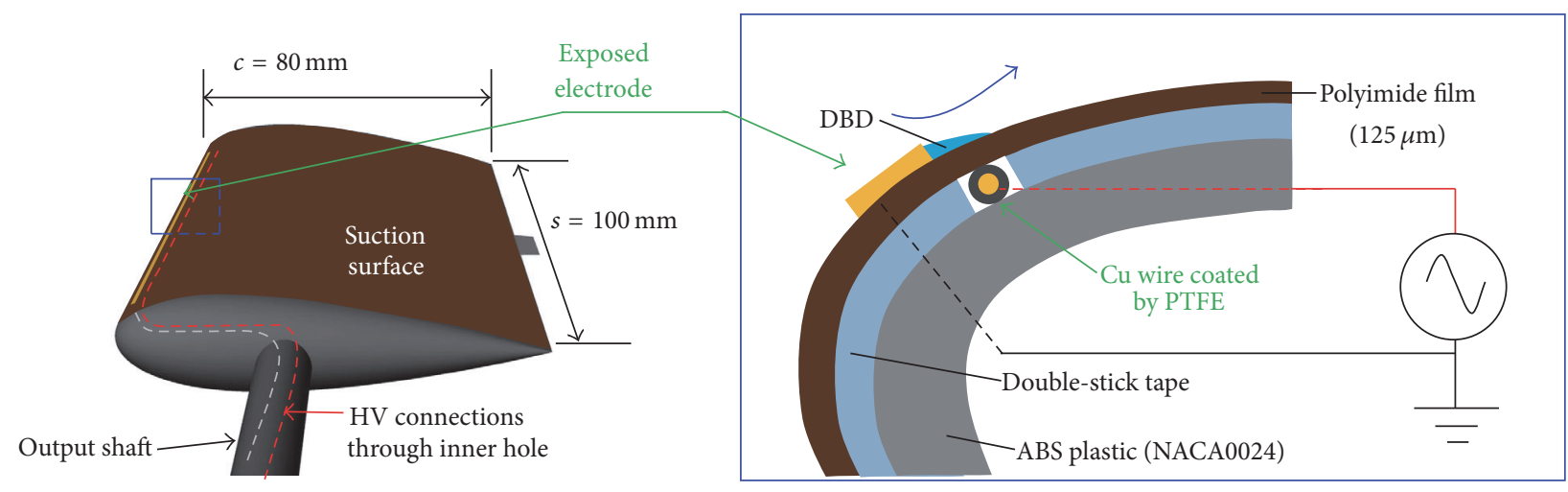

FIGURE 4: String-type DBD plasma actuator constructed in suction surface near the leading edge of NACA0024.

control of unsteady flow separation. The side wall of the test section near the airfoil suction surface was hinged at $400 \mathrm{~mm}$ downstream of the entrance and was pivoted over a range of $0^{\circ} \leq \theta \leq 16^{\circ}$, where $\theta$ is the angle between the pivoting wall and the stationary wall of the test section. By periodically oscillating the plate over a range of $0^{\circ} \leq \theta \leq 12^{\circ}$, using a DC motor, the flow separation was artificially enhanced or mitigated up to $1 \mathrm{~Hz}$. DOS (dioctyl sebacate) droplets atomized by a Laskin nozzle to the order of $1 \mu \mathrm{m}$ diameter were introduced into the flow as seeding particles, and the flows around the NACA0024 airfoil were visualized using a $30 \mathrm{~mJ} /$ pulse double-pulse Nd:YAG laser (Litron Lasers, NANO S30-15PIV), with flow-image pairs acquired at $3.75 \mathrm{~Hz}$ using a cross-correlation camera (TSI Inc., PIVCAM13-8, $1,280 \times 1,024$ pixel resolution). The velocity vectors in the plane of the $x-y$ cross section at the midspan of the airfoil and DBD plasma actuator were analyzed using particle image velocimetry (PIV).

The response of feedback control in quiescent flow was estimated by inputting thermal strain and measuring the time delay between the input signal and output response. This was found to be less than $5 \mathrm{~ms}$. In addition, lift $(L)$ and drag $(D)$ forces were measured using a three-component force transducer (Kyowa, LSM-B-5NSA37) located outside the test section, as shown in Figure 3 . This system has a temperature correction function, so that the temperature drift during the experiments was automatically corrected. The force measurement resolution was stated as $0.001 \mathrm{~N}$ in the specifications, but our own calibration using standard weights showed the repeatability of the lift and drag force measurements to be less than $0.01 \mathrm{~N}$.

\section{Results and Discussion}

3.1. Open-Loop Control of Flow Separation. In the present study's string-type DBD plasma actuator, a copper wire coated with PTFE functioned as the actuator $(\mathrm{Cu}: 0.076 \mathrm{~mm}$ in diameter; PTFE: $0.1 \mathrm{~mm}$ in thickness; total: $0.3 \pm 0.02 \mathrm{~mm}$ in diameter). The wire was placed at $x=0.06 \mathrm{~mm}$ on the suction surface using double-sided tape, and the surface of the NACA0024 was wrapped in a polyimide sheet of $125 \mu \mathrm{m}$ in thickness. An exposed electrode made of copper film, $35 \mu \mathrm{m}$ in thickness and $80 \mathrm{~mm}$ long in the spanwise direction, was attached to the polyimide sheet surface, and DBD plasma was formed near $x / c=0.05$ by applying high voltages using a power supply (PSI Inc., PG1040F). The power consumption of the string-type $\mathrm{DBD}$ plasma actuator $\left(P_{\mathrm{PA}}\right)$ was estimated using the $V-Q$ Lissajous method, as described in [21]. Figure 5(a) shows the electric circuit diagram, in which the plasma actuators (capacitance: $C_{\mathrm{PA}}$ ) and an additional capacitor (capacitance: $C_{r}=22 \mathrm{pF}$ ) were connected in series. When voltages of $V_{\mathrm{PA}}$ and $V_{r}$ are applied to the plasma actuator and additional capacitor, the respective electric charges $\left(Q_{\mathrm{PA}}\right.$ and $\left.Q_{r}\right)$ are equal: $Q_{\mathrm{PA}}=Q_{r}=$ $C_{\mathrm{PA}} V_{\mathrm{PA}}=C_{r} V_{r}$. Therefore, $\mathrm{Q}_{\mathrm{PA}}$ can be evaluated in terms of $Q_{r}$ by measuring $V_{r}$, since $C_{r}=22 \mathrm{pF}$ is known. The $V-Q$ Lissajous figure can be plotted by measuring $V_{\mathrm{PA}}$ using a high voltage probe, and $P_{\mathrm{PA}}$ is calculated as the product of $f_{p} \times$ $S_{V Q}$, which is the area encompassed by the Lissajous figure, as shown in Figure 5(b). In our previous study, involving instantaneous measurement, a tangential jet with maximum velocity $u_{\text {j-max }}=0.8 \mathrm{~m} / \mathrm{s}$ was induced from the leading edge by a sheet-type DBD plasma actuator with a $125 \mu \mathrm{m}$ thick polyimide sheet, through the application of voltage $V_{p-p}=$ $8.0 \mathrm{kV}$ at frequency $f_{p}=9 \mathrm{kHz}$ [15]. In this study, however, a higher voltage of $V_{p-p}=12.0 \mathrm{kV}$ at frequency $f_{p}=9 \mathrm{kHz}$ was necessary to achieve $u_{j \text {-max }}=0.8 \mathrm{~m} / \mathrm{s}$ from the exposed electrode attached to the NACA0024 airfoil, in quiescent flow, because of the increased distance between the metallic wire and exposed electrode. The $P_{\mathrm{PA}}$ of the plasma actuator of $80 \mathrm{~mm}$ long in the spanwise direction was estimated to be $2.5 \pm 0.4 \mathrm{~W}(\approx 31 \mathrm{~W} / \mathrm{m})$, as the average of 10 values.

Before conducting feedback control of flow separation, PIV measurements of the instantaneous velocity distributions around the NACA0024 (fixed at $\alpha=12^{\circ}$ ) were conducted under open-loop control conditions, at fixed angles to the wind tunnel side wall between $0^{\circ} \leq \theta \leq 16^{\circ}$. The free-stream velocity $\left(U_{\infty}\right)$, calculated using PIV by averaging 50 velocity distributions near the upstream region of the leading edge, was set at $U_{\infty}=10 \mathrm{~m} / \mathrm{s}$ at $\alpha=12^{\circ}$ and $\theta=$ $0^{\circ}$, under steady-state conditions. When $U_{\infty}$ under steadystate conditions was adopted as the characteristic velocity, the Reynolds number and velocity ratio of the tangential jet were $\operatorname{Re}=U_{\infty} c / v=5.3 \times 10^{4}$ and $u_{j \text {-max }} / U_{\infty}=0.08$, respectively. 


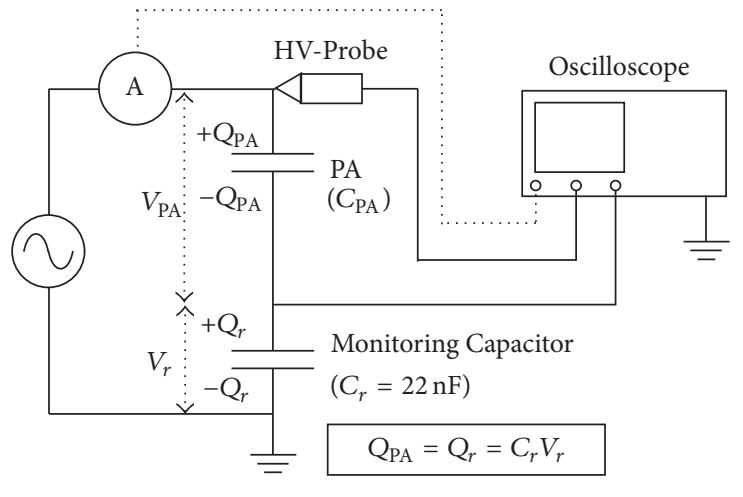

(a)

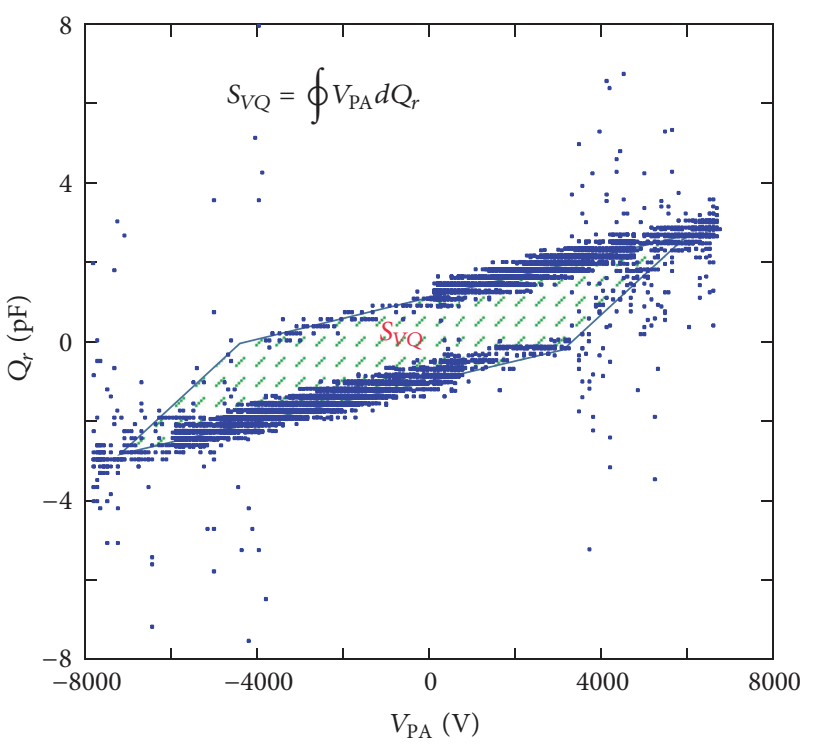

(b)

FIgURE 5: Power consumption evaluation $\left(P_{\mathrm{PA}}\right)$ of string-type DBD plasma actuator by means of $V$-Q Lissajous method. (a) Electric circuit diagram; (b) $V$-Q Lissajous figure by applying $V_{p-p}=12.0 \mathrm{kV}$ at frequency $f_{p}=9 \mathrm{kHz}$. $P_{\mathrm{PA}}$ is calculated as the product of $f_{p} \times S_{V Q}$.

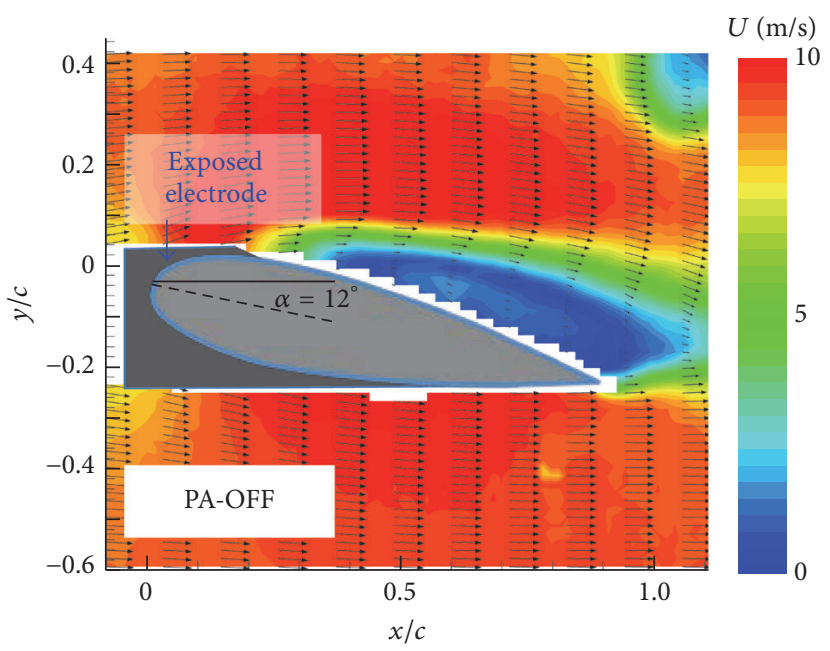

(a)

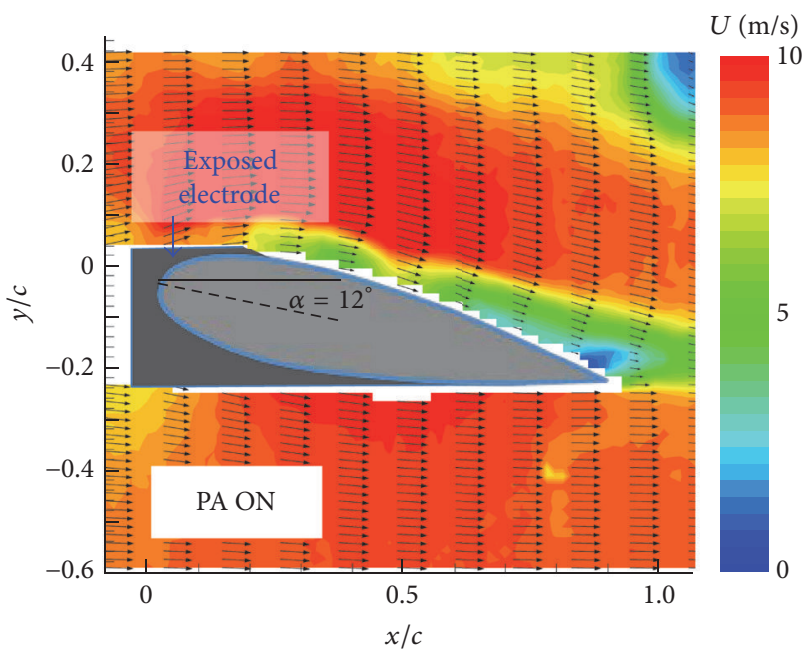

(b)

Figure 6: Time-averaged velocity distributions around the NACA0024 (50 times) at $\alpha=12^{\circ}$ and $\theta=2^{\circ}$, (a) PA-OFF; (b) PA-ON by string-type DBD plasma actuator placed at $x / c=0.05$.

For example, flow separation occurred from the leading edge at $\theta=2^{\circ}$ in the case of no flow control (PA-OFF) (Figure 6(a)), based on the time-averaged velocity distributions around the NACA0024 (50 times). On the other hand, Figure 6(b) shows the time-averaged (50 times) velocity distributions when a tangential jet was continuously induced from the stringtype DBD plasma actuator (PA-ON), confirming that flow separation was considerably mitigated by flow control.

3.2. Flow Separation Detection with Open-Loop Control of Flow Separation. An FBG strain measurement system, which can precisely detect minute elastic deformation of an optical fiber, was used to detect flow separation. FBG sensors are generally used, in various research fields such as architecture and civil engineering, for measurement of structural distortion, as described in [22]. As shown in Figure 7, approximately 2,000 gratings are installed in the core of the optical fiber (less than $10 \mu \mathrm{m}$ in diameter) in a section of the FBG sensor. A broadband laser with wavelengths ranging from 1,500 to $1,590 \mathrm{~nm}$ is shone down the core of optical fiber, and light is reflected from the grating with a wavelength corresponding to the Bragg wavelength, $\lambda_{B}=$ $2 n_{0} \Lambda$, where $n_{0}$ is the fiber refractive index and $\Lambda$ is the grating interval. When the FBG sensor is strained by external 


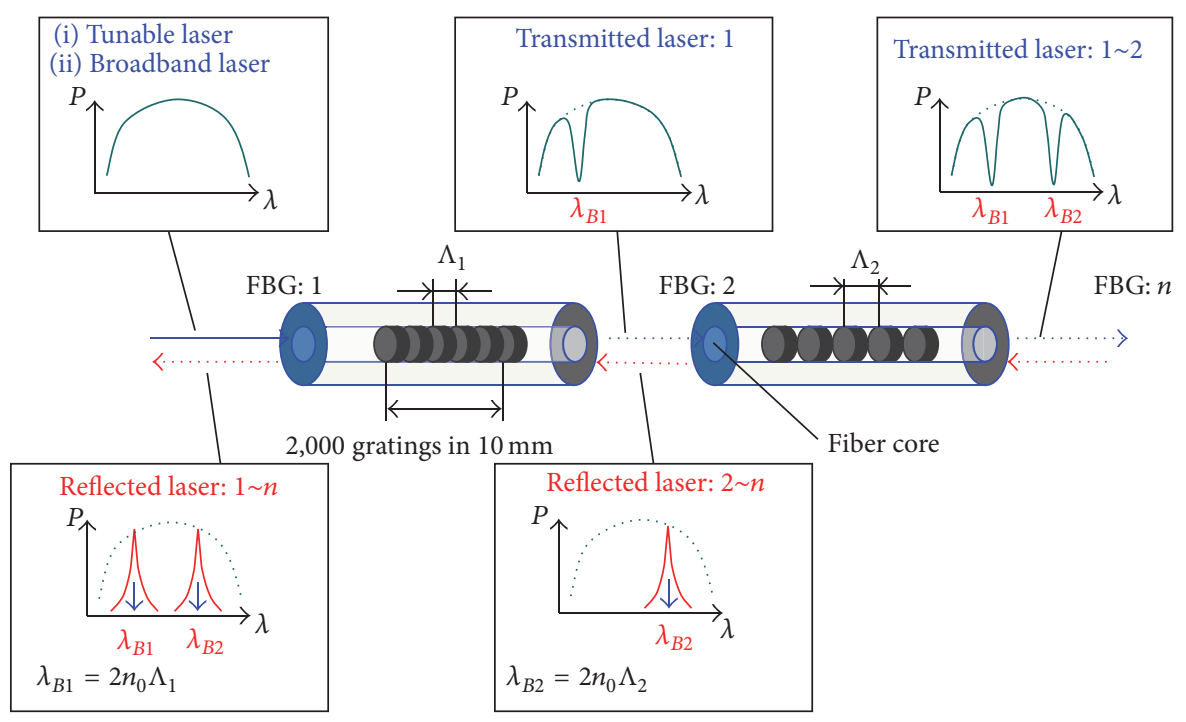

FIGURE 7: Schematic diagram of strain measurement method by FBG sensor.

forces (mechanical or thermal), a shift is detected in the reflected wavelength, enabling measurement of the strain near the root of the cantilever beam. In this way, multiple sensors with different grating intervals $\left(\Lambda_{1}, \Lambda_{2}, \ldots, \Lambda_{n}\right)$ can be introduced into the same optical fiber, in series, simply by varying the nominal wavelength of the respective gratings $\left(\lambda_{B 1}, \lambda_{B 2}, \ldots, \lambda_{B n}\right)$. In this study, fluctuations in the Bragg wavelength were measured at a maximum sampling rate of $f_{B}=1 \mathrm{kHz}$, using an FBG sensor system (Micron Optics sm130). Control signals for the DBD plasma actuators were operated in real time using LabVIEW coded software.

There was a concern that the Bragg wavelength shifts would be affected by the slightly heated air advected from the surface near the exposed electrode generating DBD, when the FBG sensor was attached to the suction surface of the airfoil. Thus, as a countermeasure, the FBG was attempted to be attached to the structure modeled in the pressure surface of the NACA0024 in our previous study [18]. Figures $8(a)-8(c)$ show the basic structure of the FBG flow sensor here employed for flow separation detection. An optical fiber (outer diameter: $250 \mu \mathrm{m}$ ) was inserted into the hollow NACA0024 airfoil. The cantilever, a monocoque structure modeled in the pressure surface of the airfoil, was $10 \mathrm{~mm}$ wide by $43 \mathrm{~mm}$ long by $0.5 \mathrm{~mm}$ thick. The cantilever root was located at $x=0.53 c$, and the cantilever tip protruded $5 \mathrm{~mm}$ beyond the trailing edge of the airfoil. In the primary FBG flow sensor, the grating section is located near the exterior surface of the cantilever root, as illustrated in Figure 8(b). Figure 9(a) shows the time-series of Bragg wavelength fluctuations for 20 seconds under PAOFF conditions. It was confirmed that there were regions with relatively larger amplitude of $\lambda_{B}$ in approximately $4 \mathrm{~s}$ intervals when the movable section of the wind tunnel was oscillated at $f_{w}=0.27 \mathrm{~Hz}$. The $\lambda_{B}$ fluctuations with wall oscillation are analyzed in detail below; however, it was concluded that the FBG sensor detected strains at the cantilever root, through vibration of the tip where the wake flow occurred during flow separation. However, the intermediate $\lambda_{B}$ value was found to be constant, at roughly $1540.08 \mathrm{~nm}$. On the other hand, under PA-ON conditions, $\lambda_{B}$ tended to gradually increase over time, as shown in Figure 9(b). It was found that the heating of the jets, caused by the operation of the plasma actuator, affected flow separation detection, even when the FBG sensor was attached (as in Figure 8(b)) to the exterior surface of the cantilever modeled in the pressure surface of the NACA0024. Here we discuss a possibility of this phenomenon. Heated air by DBD plasma is mostly carried in the vicinity of the suction surface by the main flow. On the other hand, the exposed electrode and polyimide film (insulation layer) illustrated in Figure 4 are also heated by DBD plasma and temperature around the leading edge can rise gradually by thermal conduction. As a results, it is possible that air which flows on the pressure surface is also heated slightly near the leading edge and the Bragg wavelength reflected from a FBG sensor shifts over time by the thermal effect in the case of location of the FEB sensor attached to the exterior surface of the cantilever.

Consequently, the fiber optic was attached (as in Figure $8(\mathrm{c})$ ) to the interior surface of the cantilever, in the streamwise direction, to minimize the thermal effects of the DBD plasma. The grating section of the FBG sensor was mounted across the cantilever root in the region of $0.44<$ $x / c<0.57$. In this FBG flow detection system, the cantilever was streamlined according to the airfoil shape, so that it fit smoothly against the pressure surface of the airfoil. The $\lambda_{B}$ fluctuations were measured under the flow conditions shown in Figure 6. Figure 10(a) shows the $\lambda_{B}$ fluctuations at $\theta=$ $2^{\circ}$, under PA-OFF (Figure 6(a)) and PA-ON (Figure 6(b)). The $\lambda_{B}$ measurements were conducted for 10 seconds at a sampling frequency of $f_{B}=1 \mathrm{kHz}$. The string-type DBD plasma actuator was operated between $4.0 \leq t \leq 6.5 \mathrm{~s}$. When the tangential jets were induced (in PA-ON), the amplitude of the $\lambda_{B}$ fluctuations dramatically decreased in comparison to the PA-OFF conditions. The standard deviation in the Bragg 


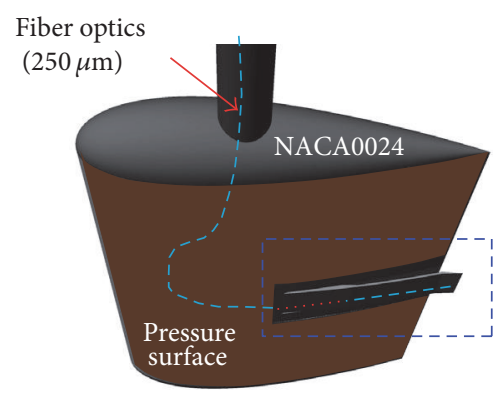

(a)

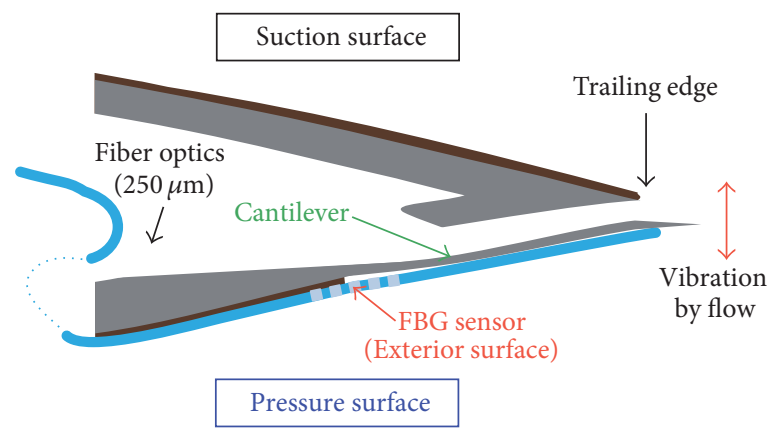

(b)

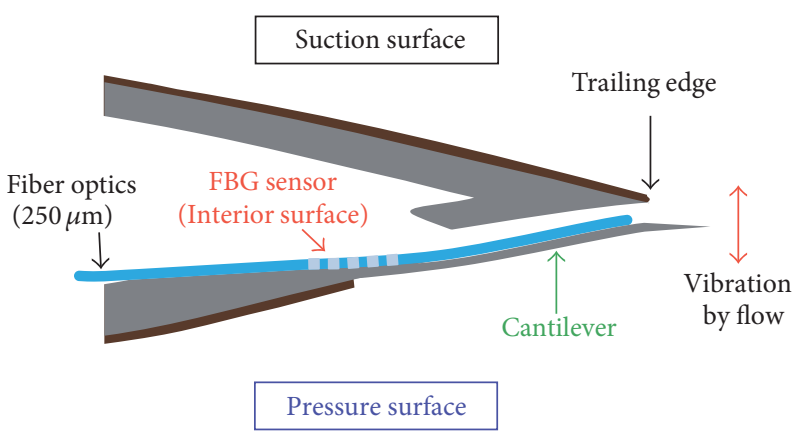

(c)

FIGURE 8: Schematic illustrations of FBG flow sensor constructed in pressure surface of NACA0024. (a) An optical fiber is inserted in the inside of hollow NACA0024 airfoil. Detections of flow separation are tried by attaching the FBG sensor (b) on exterior surface of cantilever and (c) on interior surface of cantilever.

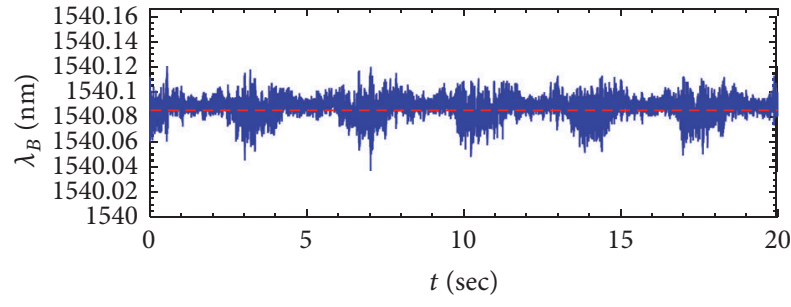

(a)

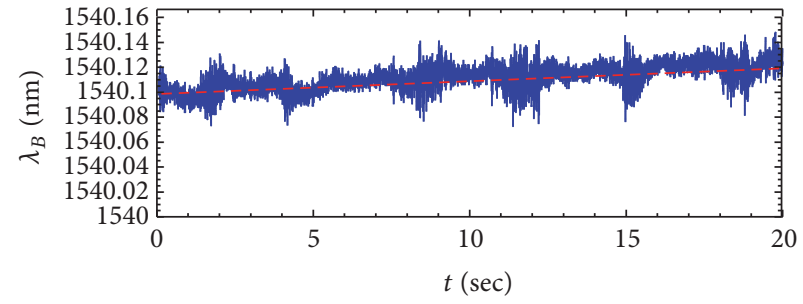

(b)

FIgURE 9: Time-series of Bragg wavelength fluctuations $\left(\lambda_{B}\right)$ for 20 seconds under PA-OFF and PA-ON conditions which are detected by FBG sensor attached to exterior surface of cantilever (Figure 8(b)). (a) Under PA-OFF, intermediate $\lambda_{B}$ value was found to be constant, at roughly $1540.08 \mathrm{~nm}$. (b) On the other hand, $\lambda_{B}$ tended to gradually increase over time under PA-ON.

wavelength $\left(\lambda_{B}^{\prime}\right)$ under PA-OFF and PA-ON, as a function of $\theta$, is plotted in Figure $10(\mathrm{~b})$. In the case of PA-OFF, $\lambda_{B}$ tended to decrease with increasing $\theta$. It should be noted that $\lambda_{B}^{\prime}$ at $\theta \leq 4^{\circ}$ was significantly higher than $\lambda_{B}^{\prime}$ at $\theta \geq 6^{\circ}$. These characteristics are consistent with the PIV results, which showed that flow separation clearly occurred at $\theta \leq 4^{\circ}$. When flow separation occurs near the airfoil, the fluid motion near the trailing edge becomes unsteady. Therefore, the amplitude of tip deflection in the cantilever beam is greater than in the case of attached flow. In the present study, when the DBD plasma actuator was activated and tangential jets were induced from $x / c=0.05, \lambda_{B}^{\prime}$ was immediately reduced to less than $0.003 \mathrm{~nm}$ at every $\theta$. This implies that flow separation was successfully mitigated.
In conjunction with the acquisition of Bragg wavelength shift data, the drag $(D)$ and lift $(L)$ forces were measured (Figure 11), using a three-component force balance system, under the same conditions as in Figures 6 and 10, in order to compare the results with those obtained using PIV and the FBG sensor. The standard deviations in $L$ and $D$ over $2.0 \mathrm{~s}$ were adopted as error bars under PA-ON and PA-OFF, respectively. It is remarkable that $D$ decreased more than $20 \%$ and $L$ increased by $200 \%$ to $300 \%$, when flow separation was mitigated by the string-type DBD plasma actuator. With larger $\theta$, the effects of flow control were reduced, though $D$ and $L$ were both slightly improved with the use of the stringtype DBD plasma actuator. Based on the results obtained in the open-loop control of flow separation, the string-type 


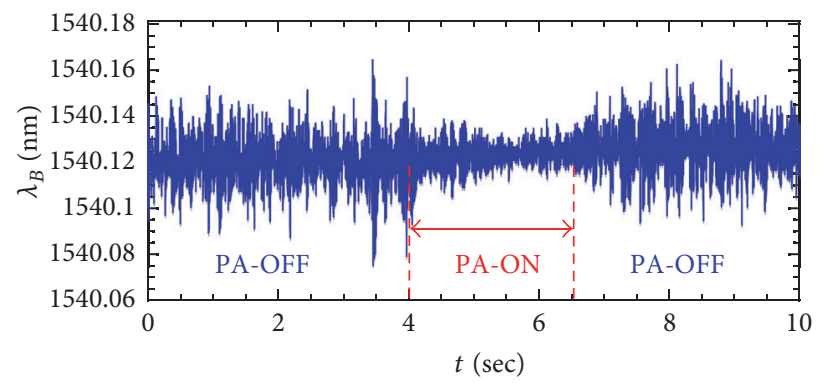

(a)

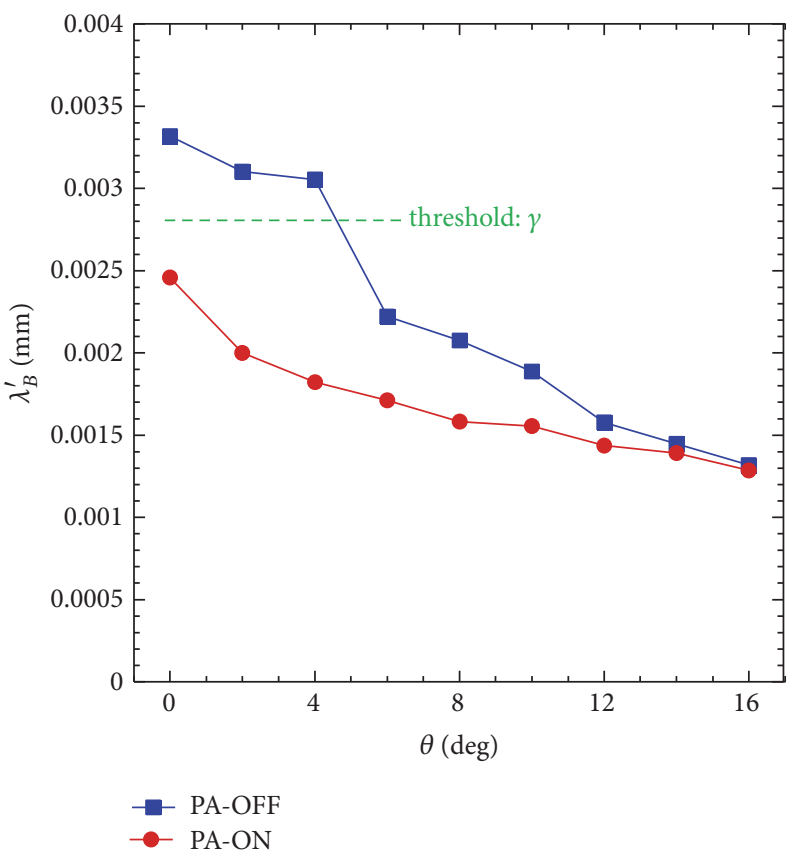

(b)

Figure 10: (a) $\lambda_{B}$ fluctuations under PA-OFF and PA-ON which are detected by FBG sensor attached to interior surface of cantilever (Figure $8(\mathrm{c}))$. (b) Standard deviations of Bragg wavelength $\left(\lambda_{B}^{\prime}\right)$ as a function of $\theta$.

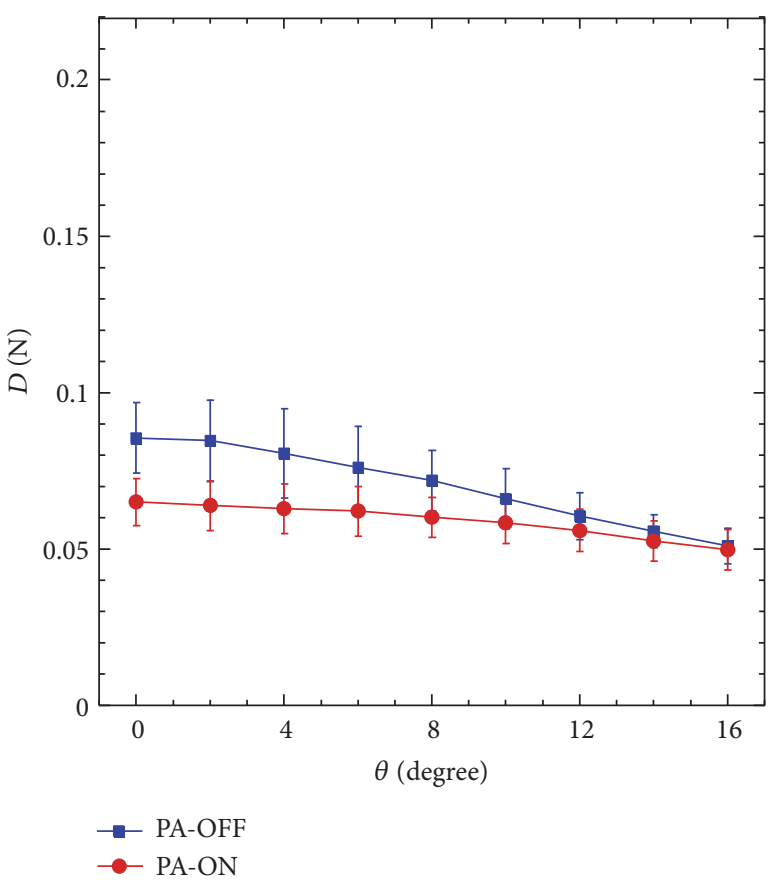

(a)

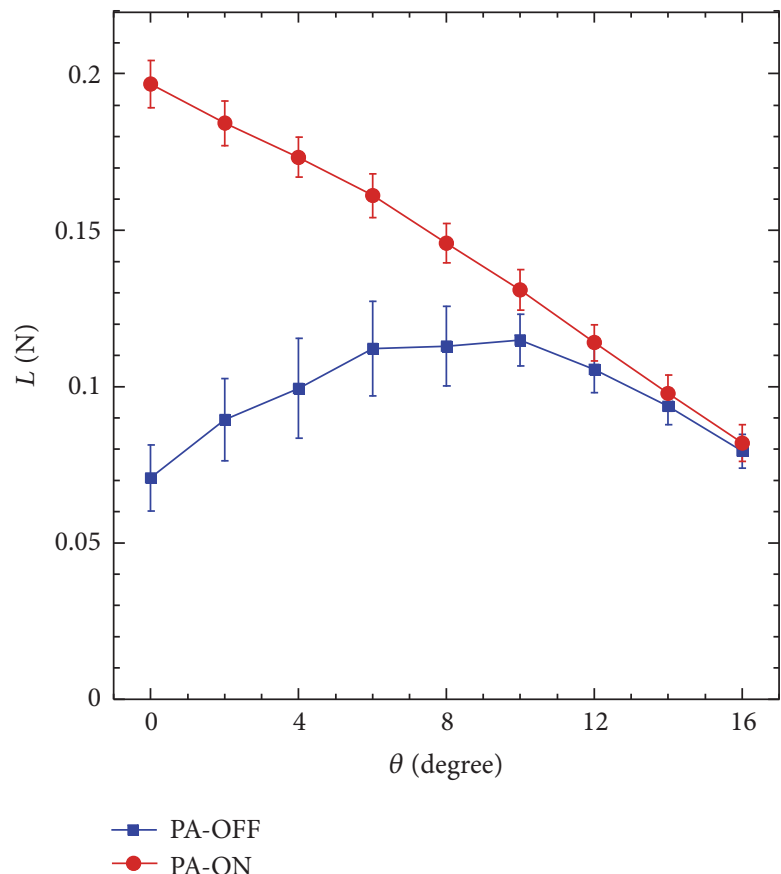

(b)

FIGURE 11: Enhancements of aerodynamic properties by open-loop control of flow separation, (a) drag force; (b) lift force.

DBD plasma actuator used in this study is considered to be a promising device for mitigating flow separation under lower $\theta$ conditions, and closed-loop control of flow separation is possible by setting a threshold value of $\lambda_{B}^{\prime}=0.0028$ for inducing the tangential jets.
3.3. Closed-Loop Control of Flow Separation around the NACA002 with Periodic Wall Oscillation. To assess the effectiveness of the flow separation control system with DBD plasma actuator and FBG flow sensor, a demonstration of closed-loop control with periodic flow separation was 


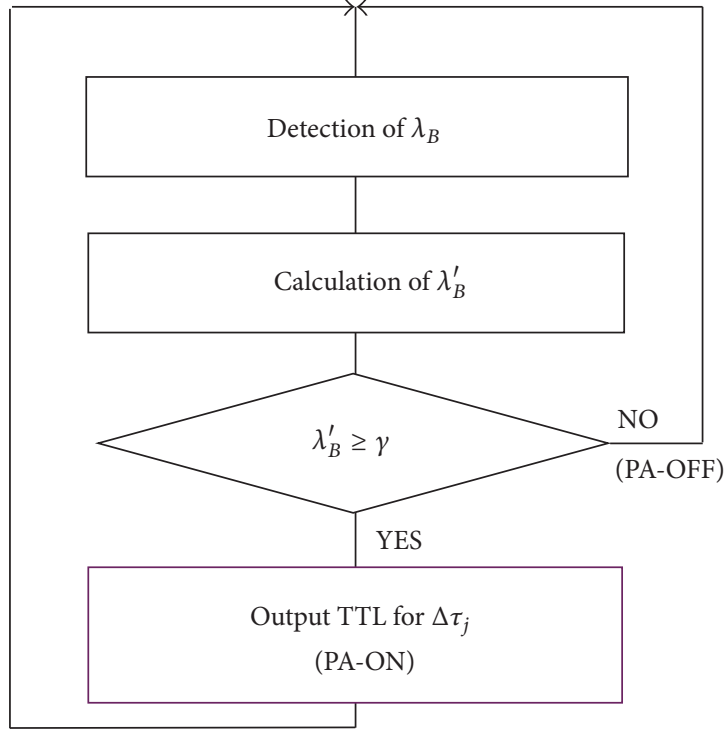

(a)
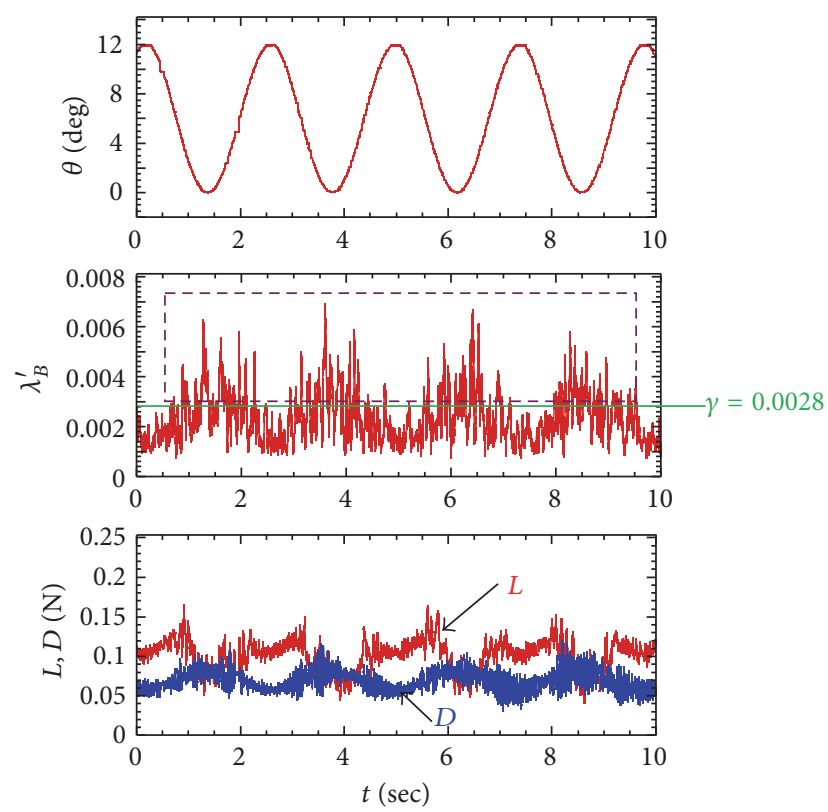

(b)

Figure 12: (a) Flowchart for the closed-loop control of flow separation. (b) $\theta$ time-series, running $\lambda_{B}^{\prime}, L$, and $D$ fluctuations for 10 s. The running $\lambda_{B}^{\prime}$ at a given time was evaluated using the past 50 values for $\lambda_{B}$. Flow separation occurs in the region of $\theta \leq 4^{\circ}$ when the running $\lambda_{B}^{\prime}$ is larger than $\gamma=0.0028$.

conducted based on the threshold value $(\gamma)$ of $\lambda_{B}^{\prime}$ (Figure 10(b)). Figure 12(a) shows the flowchart for the closedloop control of flow separation conducted in the study. The wind tunnel side wall was periodically oscillated (back and forth) from 0 to $12^{\circ}$ by a stepping motor at frequency $f_{w} \approx$ $0.42 \mathrm{~Hz}$, which periodically promoted (or mitigated) flow separation over time. As reported in the previous section, flow separation was confirmed at $\theta \leq 4^{\circ}$ when the pivoting wall was stationary. Figure 12(b) shows the $\theta$ time-series, running $\lambda_{B}^{\prime}, L$, and $D$ fluctuations for $10 \mathrm{~s}$. The running $\lambda_{B}^{\prime}$ was a standard deviation of $\lambda_{B}$, calculated for a sampling duration of $\Delta \tau_{\mathrm{STD}}=0.05 \mathrm{~s}$ in real time. Since the sampling frequency of $\lambda_{B}$ was $f_{B}=1 \mathrm{kHz}$, the running $\lambda_{B}^{\prime}$ at a given time was evaluated using the past 50 values for $\lambda_{B}$. Their parameters were found to vary periodically according to the wall oscillation, at approximately $2.4 \mathrm{~s}$ intervals, which was roughly compatible with $1 / f_{w}$. As with the stationary results (Figure 10(b)), it was considered that flow separation occurred in the region of $\theta \leq 4^{\circ}$, with dynamic movement of the side wall, because the running $\lambda_{B}^{\prime}$ in Figure 12(b) is larger than $\gamma=0.0028$. Figure 13 shows a series of instantaneous velocity distributions $(1 / 3.75 \approx 0.27$ s intervals) measured by $\mathrm{PIV}$, with periodic wall oscillation under PA-OFF conditions. It was also confirmed that the main flow was separated dynamically from the NACA0024 airfoil in sync with the wall oscillation.

In order to evaluate the flow separation control effects of the feedback system, tangential jets were induced from the exposed electrode of the string-type DBD plasma actuator for a certain duration $\left(\delta \tau_{j}\right)$, once the running $\lambda_{B}^{\prime}$ crossed the threshold value shown in Figure 14(a). Although the flow conditions around the NACA0024 were slightly different with wall oscillation than those observed when the angle of the pivoting wall remained constant, due to the influence of largescale vortices on the wake flow, $\gamma=0.0028 \mathrm{~nm}$ was adopted as the threshold for inducing tangential jets with the stringtype DBD plasma actuator. With the periodic wall oscillation shown in Figure 14(b), the lift and drag forces were measured in parallel with evaluation of the running $\lambda_{B}^{\prime}$ for $\Delta \tau_{\mathrm{STD}}=$ 0.05 s. Figure 14 (c) shows the time-series for $L$ and $D$ over $10 \mathrm{~s}$, when the jets induced by the DBD plasma actuator were injected for $\Delta \tau_{j}=0.3 \mathrm{~s}$ beginning when $\lambda_{B}^{\prime}$ crossed the 0.0028 threshold (dotted line). In the light-blue areas of Figure 14(c), $5 \mathrm{~V} \mathrm{DC}$ (TTL) was inputted to the power supply, and a voltage of $V_{p-p}=12.0 \mathrm{kV}$ with $f_{p}=9 \mathrm{kHz}$ was applied to the string-type $\mathrm{DBD}$ plasma actuator (PA-ON). In comparison with Figure 12(b), we can see an overall reduction in the amplitude of $\lambda_{B}^{\prime}$. In addition, it is remarkable that $L$ increases immediately when $\lambda_{B}^{\prime}$ exceeds $\gamma$, and then $\lambda_{B}^{\prime}$ returns to below $\gamma$. On the other hand, the drag force shows little variation in comparison with the lift force due to the low initial values of D.

The appearance probability $\left(P_{s}\right)$ of $\lambda_{B}^{\prime} \geq 0.0028$, defined as $P_{s}=($ data point numbers larger than $\gamma) /($ total measurement point numbers), was calculated as a parameter of the flow control effect. In the case of PA-OFF, it was estimated as $P_{s} \approx 0.39$, in contrast to the value of $P_{s} \approx 0.12$ for PA$\mathrm{ON}$, with $\Delta \tau_{\mathrm{STD}}=0.05 \mathrm{~s}$ and $\Delta \tau_{j}=0.3 \mathrm{~s}$ (Figure 16). This indicated that flow separation was mitigated by $70 \%$ using this closed-loop control strategy, a result supported by the 


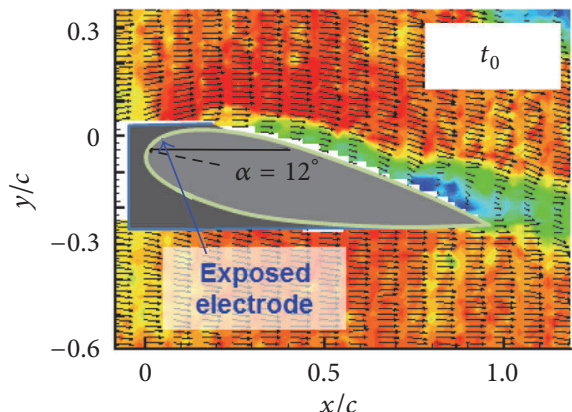

(a)

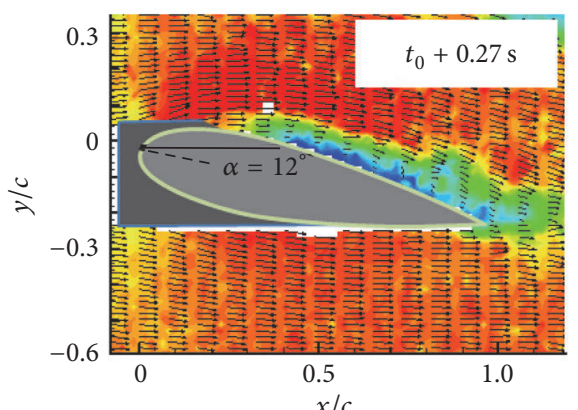

(b)

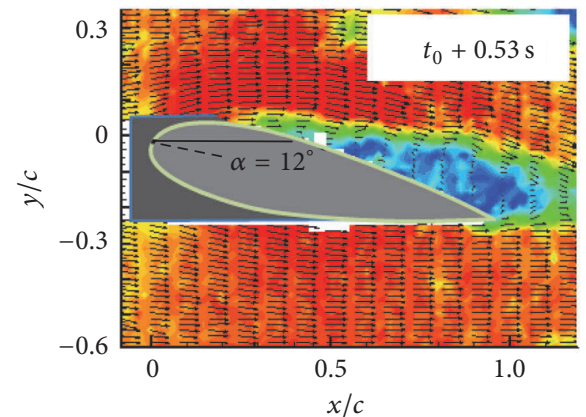

(c)

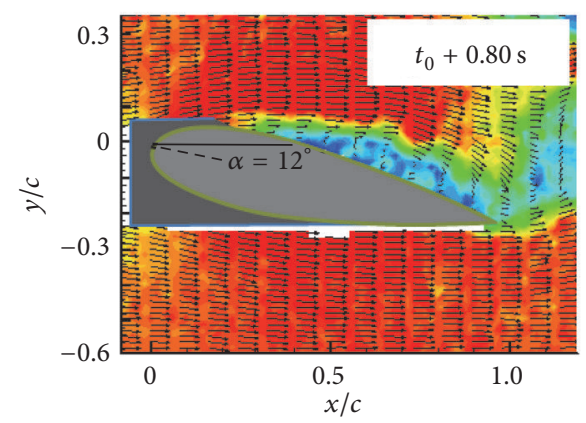

(d)
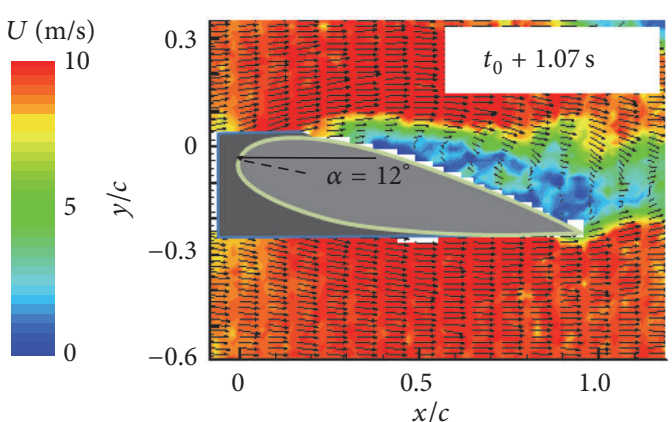

(e)
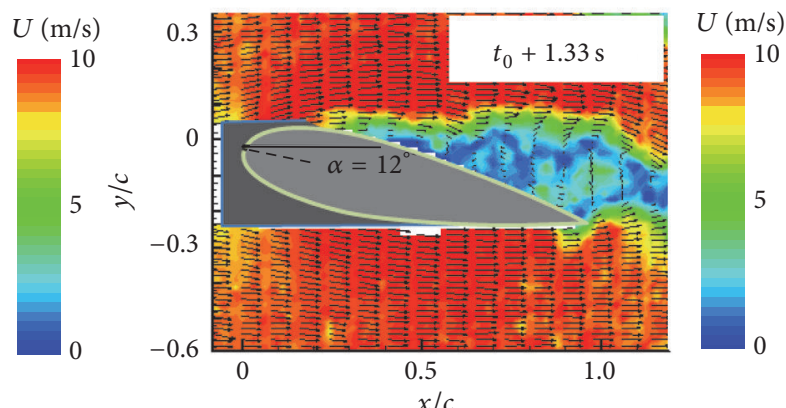

(f)
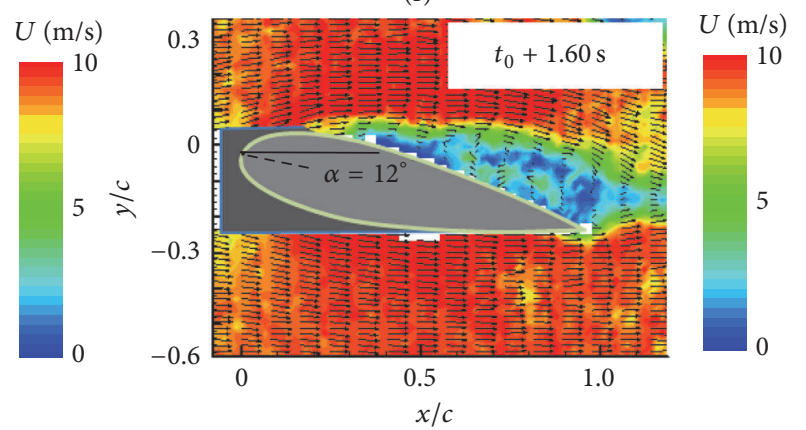

(g)

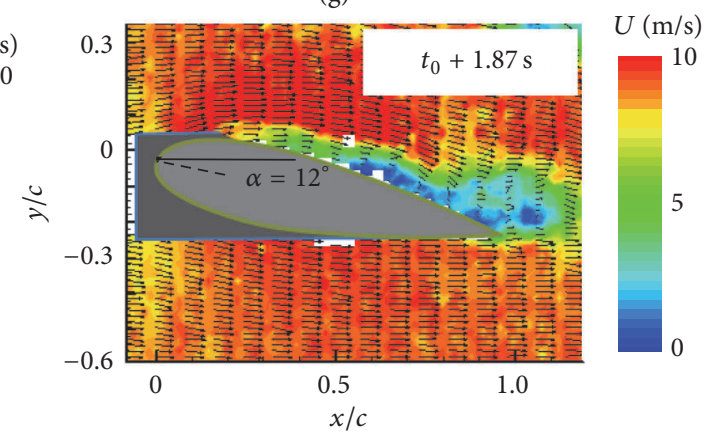

(h)

FIGURE 13: A series of instantaneous velocity distributions $(1 / 3.75 \approx 0.27 \mathrm{~s}$ intervals $)$ measured by PIV, with periodic wall oscillation under PA-OFF conditions. The main flow was separated dynamically from the NACA0024 airfoil in sync with the wall oscillation.

PIV analysis, as shown in Figure 15. Since the TTL signal was not outputted until a value of $\lambda_{B}^{\prime} \geq 0.0028$ was determined, flow separation occasionally occurred but was immediately mitigated by the jet injections.

Figure 15(f), for example, shows the velocity distributions just before flow control in response to flow separation being observed around the NACA0024. Only $1 / 3.75 \mathrm{~s} \approx 0.27 \mathrm{~s}$ later; however, flow separation was immediately mitigated by feedback control (Figure 15(g)). As shown in Figure 16, $P_{s}$ was evaluated for $\Delta \tau_{j}$, varying over a range of $0.02 \leq \delta \tau_{j} \leq$ $0.5 \mathrm{~s}$, in terms of two durations $\left(\Delta \tau_{\mathrm{STD}}=0.02 \mathrm{~s}\right.$ and $\left.0.05 \mathrm{~s}\right)$ used for calculating the running standard deviations in the 


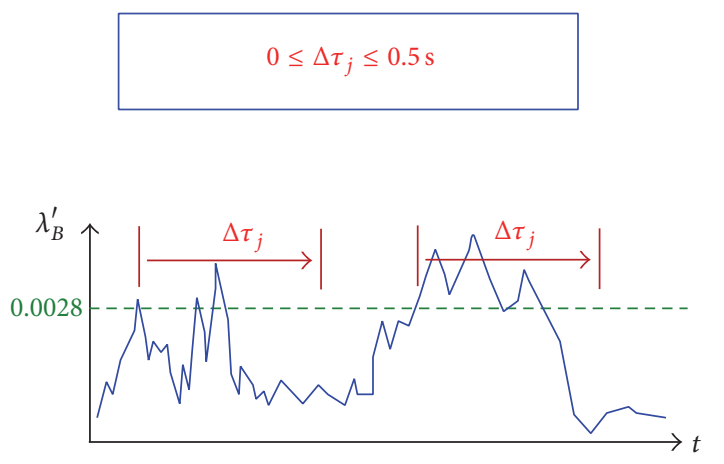

(a)

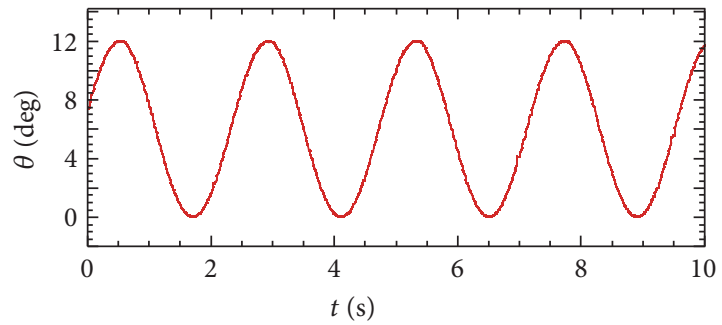

(b)

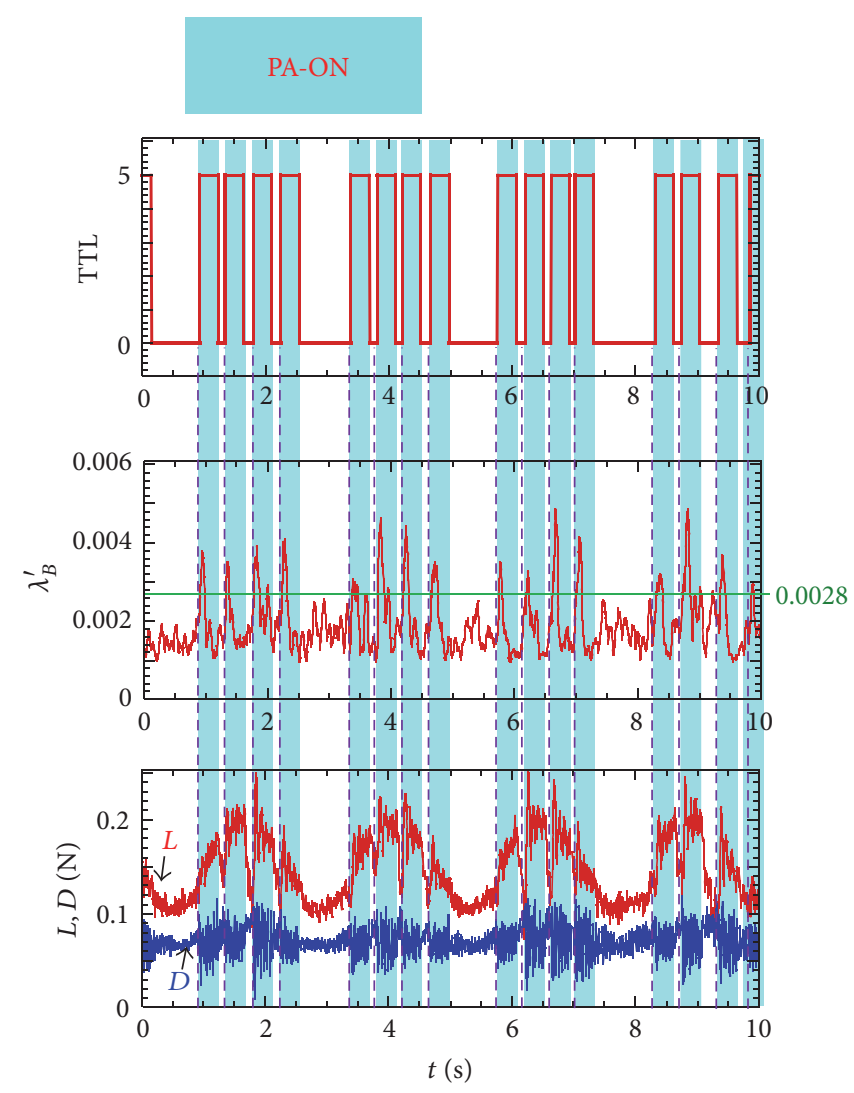

(c)

FIGURE 14: Flow separation control effects of the feedback system under periodic wall oscillation. (a) Duration $\left(\delta \tau_{j}\right)$ for inducing tangential jets from the exposed electrode of the string-type DBD plasma actuator, once the running $\lambda_{B}^{\prime}$ crossed the threshold value. (b) $\theta$ variations under periodic wall oscillation. (c) Time-series for TTL, $\lambda_{B}^{\prime}$, $L$, and $D$ over $10 \mathrm{~s}$ in case of $\Delta \tau_{\mathrm{STD}}=0.05 \mathrm{~s}$. Jets induced by the DBD plasma actuator are injected for $\Delta \tau_{j}=0.3 \mathrm{~s}$ beginning when $\lambda_{B}^{\prime}$ crossed $\gamma$. L increases immediately when $\lambda_{B}^{\prime}$ exceeds $\gamma$, and then $\lambda_{B}^{\prime}$ returns to below $\gamma$.

Bragg wavelength. It was confirmed that flow separation was effectively mitigated by reducing $\Delta \tau_{\mathrm{STD}}$ and increasing $\Delta \tau_{j}$. In order to compare the flow control effect of the feedback system, open-loop control of flow separation was performed with periodic wall oscillation (Figure 17). Tangential jets induced by the string-type DBD plasma actuator were continuously injected over $3.0 \leq t \leq 9.0 \mathrm{~s}$. It is remarkable that the running $\lambda_{B}^{\prime}$, as calculated for $\Delta \tau_{\mathrm{STD}}=0.05 \mathrm{~s}$ in real time, was clearly reduced to less than $\gamma=0.0028$ during PA$\mathrm{ON}$, and the lift force varied with the opposite phase of wall oscillation. In addition, the lift force values were significantly greater than those under PA-OFF. The velocity distributions with open-loop control of flow separation were measured using PIV (Figure 18), and it was found that the flows around the NACA0024 hugged the suction surface, with exception of the situation shown in Figure 18(a), where the velocity 


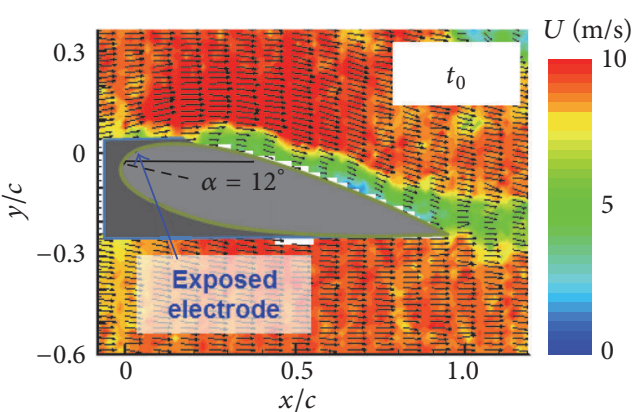

(a)

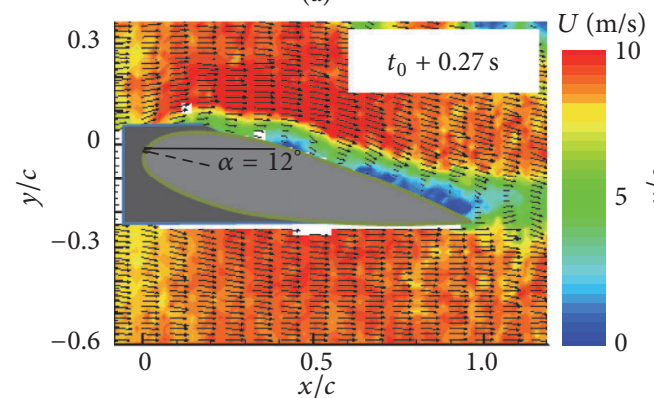

(b)

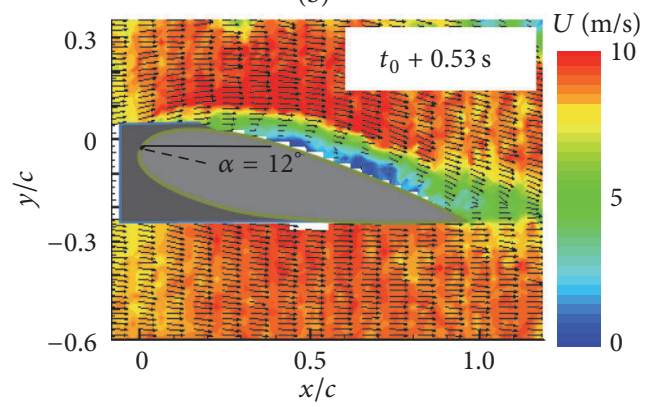

(c)

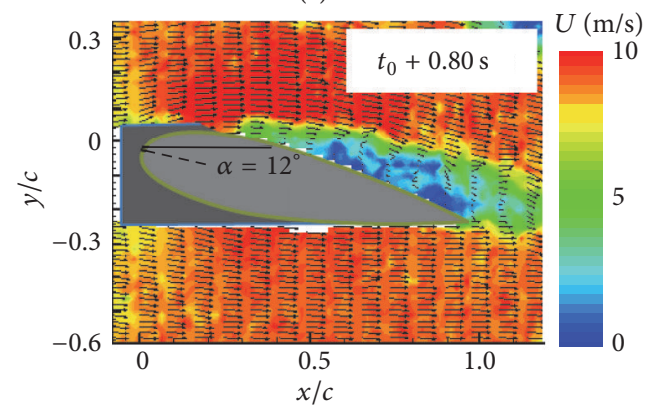

(d)

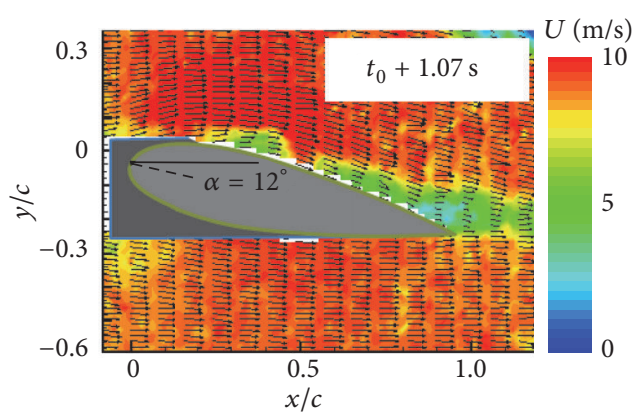

(e)
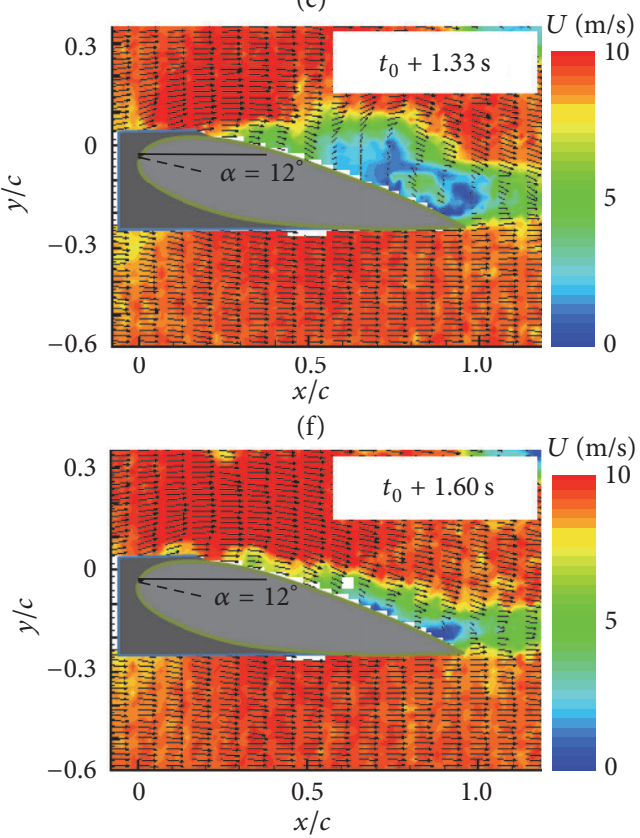

(g)

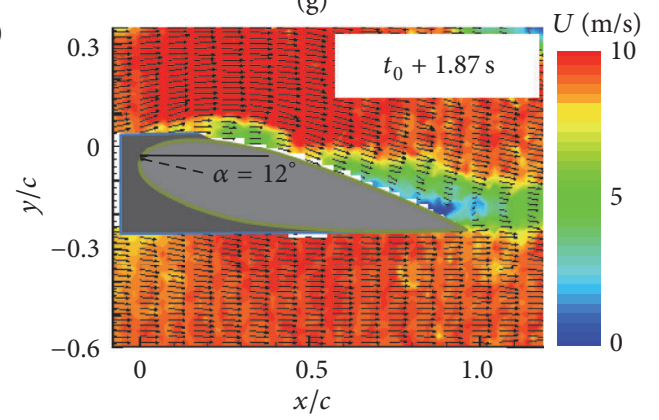

(h)

FIGURE 15: A series of instantaneous velocity distributions $(1 / 3.75 \approx 0.27 \mathrm{~s}$ intervals $)$ measured by PIV, with periodic wall oscillation under PA-ON conditions. Flow separation was mitigated by $70 \%$ using this closed-loop control strategy.

distributions were measured under PA-OFF conditions, just before PA-ON.

Based on the above results, it is considered that openloop control of flow separation is a promising method for mitigating flow separation under PA-ON conditions, in comparison with closed-loop control. However, the electric power required for operating plasma actuators can also be wasted since jets are injected even when the flow is hugging the airfoil. In this respect, feedback control of flow separation is more effective, because here the DBD plasma actuator operates only when flow conditions are determined to include flow separation. On the minus side, however, the flows around the airfoil occasionally separate (as shown in Figure 15(f)), because the system does not operate until flow separation is detected. The determinations of $\Delta \tau_{\mathrm{STD}}$ and $\Delta \tau_{j}$ are additional technical issues. When $\Delta \tau_{\mathrm{STD}}$ is greatly reduced, there is fear that the probability of erroneous determination will increase due to the detection of spiky noise in $\lambda_{B}$ and 


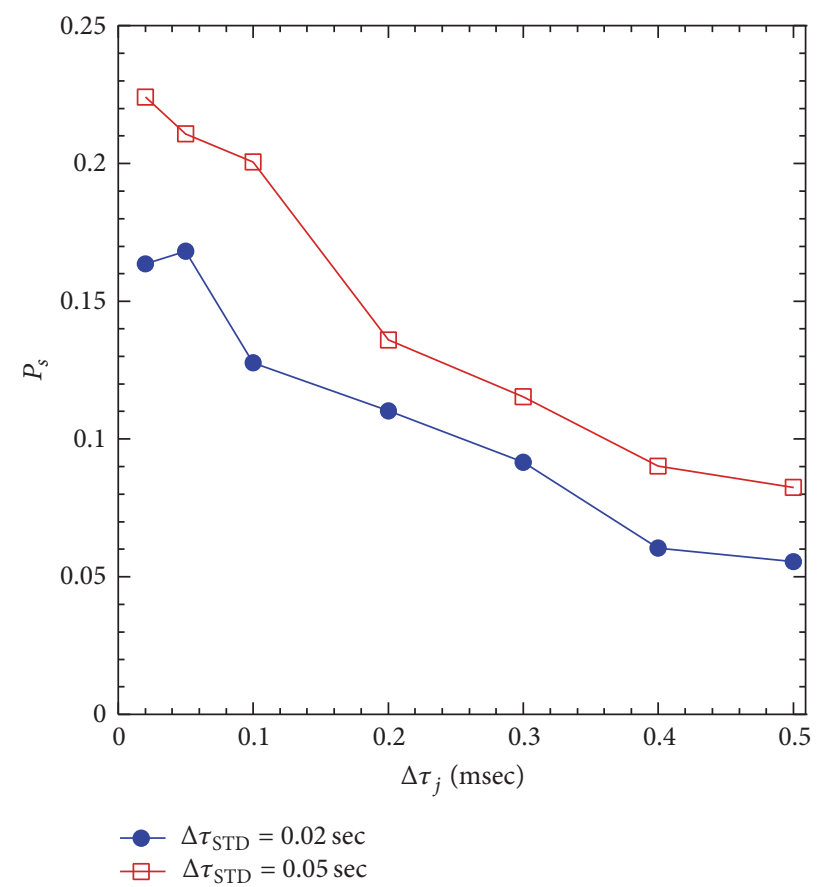

Figure 16: Appearance probability $\left(P_{s}\right)$ of $\lambda_{B}^{\prime} \geq 0.0028$ as a function of $\Delta t_{j}$.

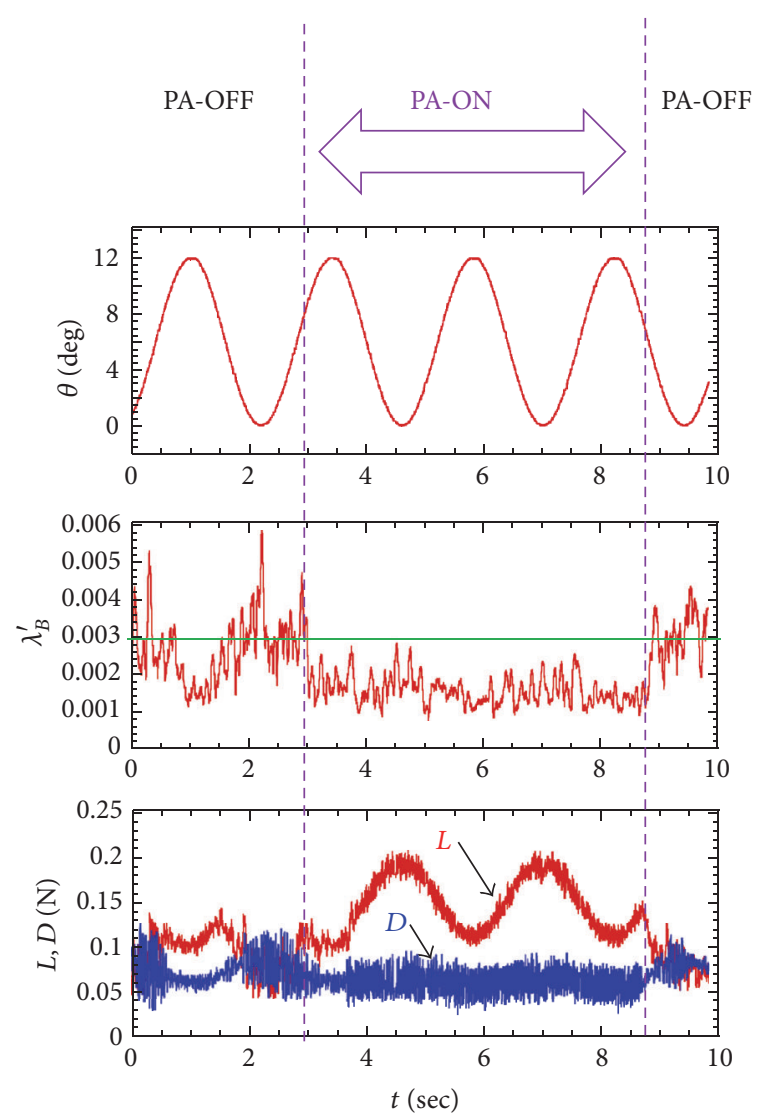

FIgURE 17: Effects under open-loop control of flow separation. Tangential jets induced by the string-type DBD plasma actuator was injected continuously in $3.0 \leq t \leq 9.0 \mathrm{~s}$. increasing $\Delta \tau_{j}$ will finally result in continuous operation of the plasma actuator and a corresponding increase in power consumption. Therefore, appropriate $\Delta \tau_{\mathrm{STD}}$ and $\Delta \tau_{j}$ values should be chosen in response to actual flow conditions, such as the typical frequency and fluctuation band of flow separation.

3.4. Future Works on Feedback Control of Flow Separation for Applying to Fluid Machinery. The feedback control of flow separation by means of string-type DBD plasma actuator and FBG flow sensor is a promising technology to realize enlargements of energy efficiency in fluid machineries which work in unsteady flow, as demonstrated by Jukes [23]. For example, this technology is applicable for wind turbines because wind conditions change by the minute in the field. Since flow separations occur occasionally, the closed-loop control system has a beneficial effect on mitigations of flow separation. At present, we are developing to fit these technologies on a $1 \mathrm{~kW}$-class wind turbine (Figure 19) in order to demonstrate a feedback control of flow separation in the natural environment. The copper wire coated with PTFE was attached to a cupper tape which was glued on the suction surface of the turbine made of a carbon-fiberreinforced plastic (CFRP). As shown in Figure 19, stringtype DBD plasma actuators was suitable for applying on 3D-shaped turbine blades although it was difficult in case of using conventional sheet-type DBD plasma actuators. By applying high voltages at radio frequencies, DBD plasma is found over the entire length of the wire as shown in Figure 19(c). It is suspected that CFRP has slight conductivity, but it is possible to prevent a short circuit because the metallic wire is previously insulated except for both free ends. This characteristic is an additional advantage of string-type DBD plasma actuators.

On the other hand, a FBG flow sensor will be constructed in the pressure surface side of turbine blade for constructing feedback control system. Therefore, a fiber optic rotary joint (FORJ), which can transfers a broadband laser and Bragg wavelength between the stationary location and FBG flow sensor, has been developed in conjunction with a power transmission system for controlling actuators from the stationary location. In our future works, quantitative evaluations of control effects will be carried out by using combining developed elements in the wind turbine system.

\section{Conclusions}

In this study, open-loop and closed-loop control of flow separation were performed using a string-type DBD plasma actuator and FBG flow sensor, on an NACA0024 airfoil, with periodic wall oscillation in a wind tunnel test section. It was shown that closed-loop feedback control was possible and resulted in a net decrease in flow separation over the periodic cycle. However, the flow conditions and control parameters were significantly limited in this study. In future work, it is necessary to investigate the control effects under a variety of flow conditions (Reynolds number, angle of attack), wall oscillation (amplitude, frequency), and control 


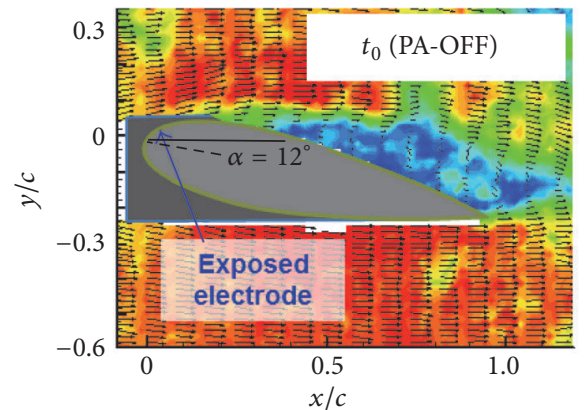

(a)

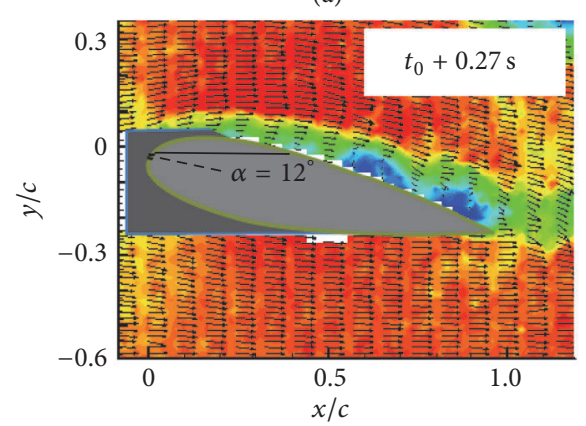

(b)

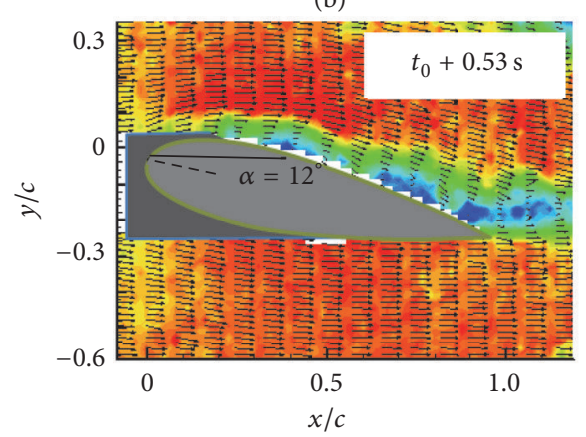

(c)

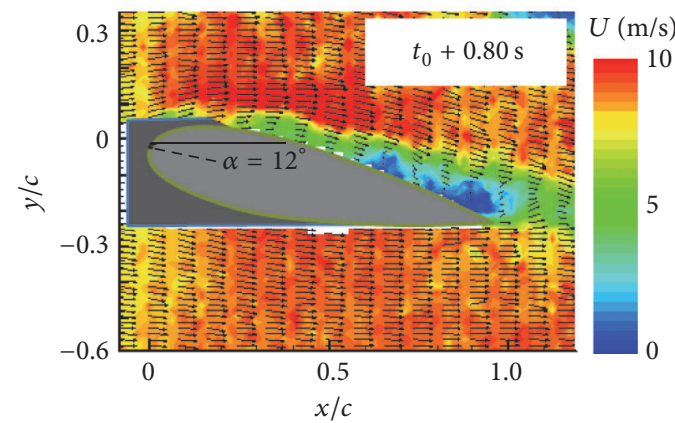

(d)

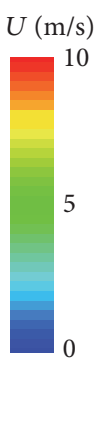

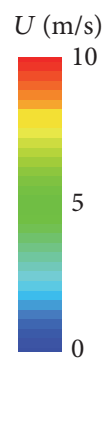

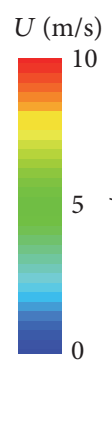

$\mathrm{m} / \mathrm{s})$

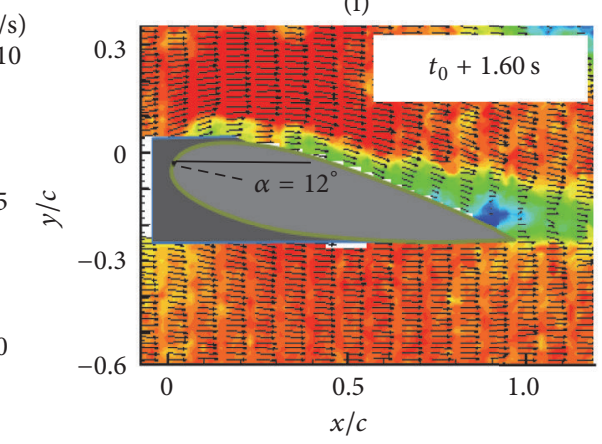

(g)

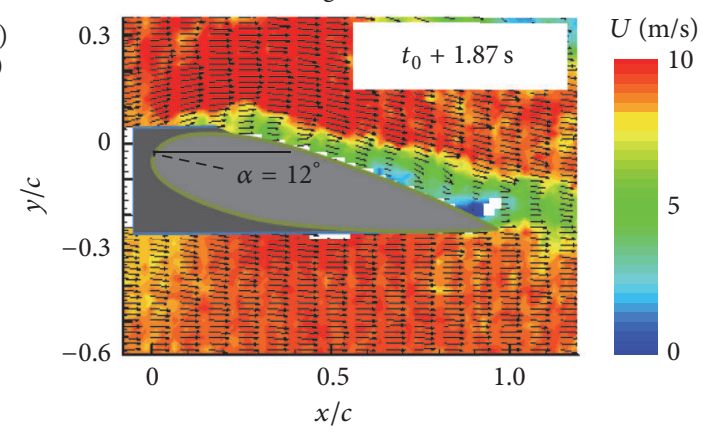

(h)

FIGURE 18: A series of velocity distributions with open-loop control of flow separation measured by PIV (1/3.75 $\approx 0.27 \mathrm{~s}$ intervals) with periodic wall oscillation. Flows around the NACA0024 hugged the suction surface, with exception of the situation under PA-OFF conditions (a), which is just before PA-ON.

algorithm (threshold, moving average scheme). In terms of control effect parameters, it was also confirmed that shorter duration for calculating the running standard deviations in Bragg wavelength $\left(\Delta \tau_{\mathrm{STD}}\right)$ and longer duration for inducing tangential jets $\left(\Delta \tau_{j}\right)$ increased the likelihood of successful flow control, but it is necessary to optimize the control effect for energy efficiency. Finally, it is considered that closed-loop control of flow separation is promising for the significantly varying flow conditions typically found in fluid machinery such as aircraft and wind turbines. Therefore, in future, the proposed system will be tested under flow conditions simulating real-world environment. 


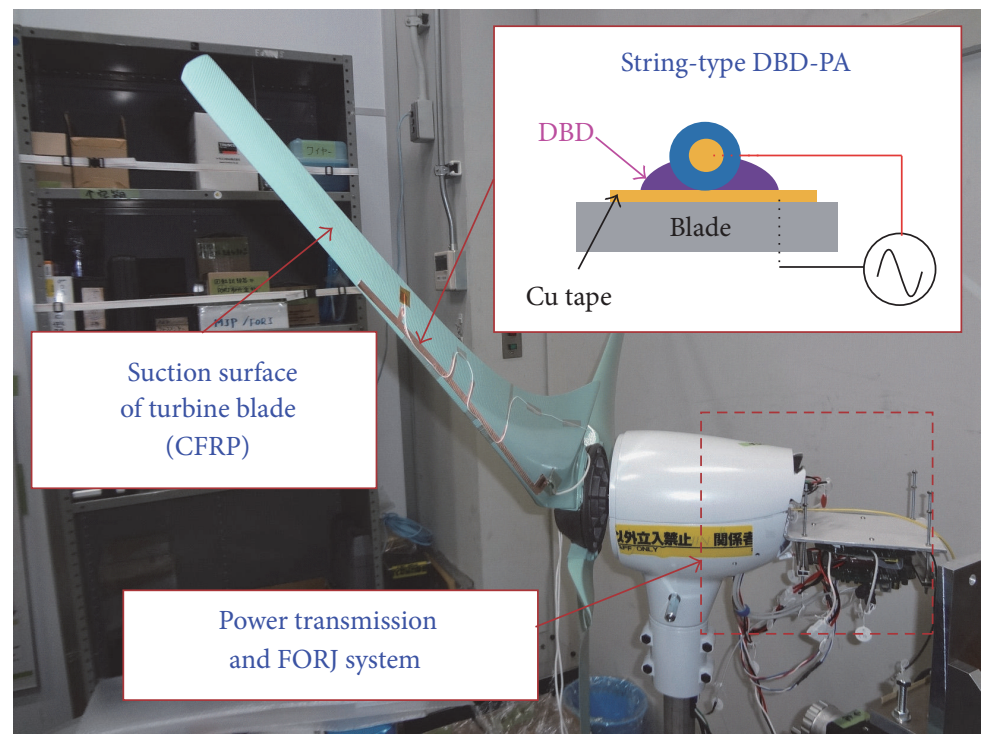

(a)

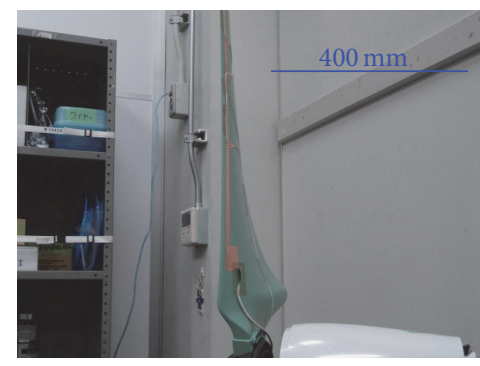

(b)

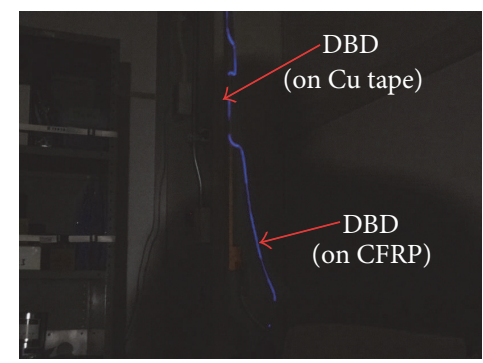

(c)

FIGURE 19: Pictures of feedback control system constructed in a $1 \mathrm{~kW}$-class wind turbine. (a) String-type DBD plasma actuator attached to the suctions surface of a turbine blade made of CFRP. Power transmission and FORJ system is connected to a rotary shaft near the tail of nacelle. (b) Pictures under illumination and (c) without ambient illumination. DBD plasma is formed around the copper wire coated with PTFE not only on copper tape, but also on CFRP surfaces.

\section{Disclosure}

Timothy Jukes's present address is Dyson Technology Ltd., Tetbury Hill, Malmesbury SN16 0RP, UK.

\section{Competing Interests}

The authors declare that they have no competing interests.

\section{Acknowledgments}

This work was supported by a "Grant for Advanced Industrial Technology Development (11B04022c)" in 2011 from the New Energy and Industrial Technology Development Organization (NEDO) of Japan.

\section{References}

[1] J. R. Roth, D. M. Sherman, and S. P. Wilkinson, "Boundary layer flow control with a one atmosphere uniform glow discharge," in Proceedings of the 36th AIAA Aerospace Sciences Meeting and Exhibit, AIAA Paper, no. 98-0328, Reno, Nev, USA, 1998.
[2] T. C. Corke, E. J. Jumper, M. L. Post, D. Orlov, and T. E. McLaughlin, "Application of weakly-ionized plasmas as wing flow-control devices," in Proceedings of the 40th AIAA Aerospace Sciences Meeting and Exhibit, AIAA Paper, no. 2002-0350, Reno, Nev, USA, 2002.

[3] W. Shyy, B. Jayaraman, and A. Andersson, "Modeling of glow discharge-induced fluid dynamics," Journal of Applied Physics, vol. 92, no. 11, pp. 6434-6443, 2002.

[4] S. Roy and D. V. Gaitonde, "Modeling surface discharge effects of atmospheric RF on gas flow control," in Proceedings of 43rd AIAA Aerospace Sciences Meeting and Exhibit, AIAA Paper, no. 2005-160, Reno, Nev, USA, 2005.

[5] J. P. Boeuf and L. C. Pitchford, "Electrohydrodynamic force and aerodynamic flow acceleration in surface dielectric barrier discharge," Journal of Applied Physics, vol. 97, no. 10, Article ID 103307, 2005.

[6] M. Forte, J. Jolibois, E. Moreau, and G. Touchard, "Optimization of a dielectric barrier discharge actuator by stationary and non-stationary measurements of the induced flow velocityapplication to airflow control," in Proceedings of the 36th AIAA Fluid Dynamics Conference and Exhibit, AIAA Paper, no. 20062863, San Francisco, Calif, USA, 2006. 
[7] E. Moreau, "Airflow control by non-thermal plasma actuators," Journal of Physics D: Applied Physics, vol. 40, no. 3, pp. 605-636, 2007.

[8] T. C. Corke, C. L. Enloe, and S. P. Wilkinson, "Dielectric barrier discharge plasma actuators for flow control," Annual Review of Fluid Mechanics, vol. 42, pp. 505-529, 2010.

[9] H. Nishida, T. Nonomura, and T. Abe, "Characterization of electrohydrodynamic force on dielectric-barrier-discharge plasma actuator using fluid simulation," World Academy of Science, Engineering and Technology, vol. 6, no. 11, pp. 254-258, 2012.

[10] M. L. Post and T. C. Corke, "Separation control on high angle of attack airfoil using plasma actuators," in Proceedings of the 45th AIAA Aerospace Sciences Meeting and Exhibit, AIAA Paper no. 2003-1024, 2003.

[11] A. Labergue, E. Moreau, N. Zouzou, and G. Touchard, "Separation control using plasma actuators: application to a free turbulent jet," Journal of Physics D: Applied Physics, vol. 40, no. 3, pp. 674-684, 2007.

[12] K. Asada, Y. Ninomiya, A. Oyama, and K. Fujii, "Airfoil flow experiment on the duty cycle of DBD plasma actuator," in Proceedings of the 47th AIAA Aerospace Sciences Meeting, AIAA Paper, no. 2009-531, Orlando, Fla, USA, 2009.

[13] T. Segawa, H. Yoshida, S. Takekawa, T. Jukes, and K.-S. Choi, "Generation of functional jet using DBD plasma actuator with facing linear electrodes," Theoretical and Applied Mechanics Japan, vol. 57, pp. 289-296, 2009.

[14] K.-S. Choi, J. Timothy, and R. Whalley, "Turbulent boundarylayer control with plasma actuators," Philosophical Transactions of the Royal Society A: Mathematical, Physical and Engineering Sciences, vol. 369, no. 1940, pp. 1443-1458, 2011.

[15] S. Walker and T. Segawa, "Mitigation of flow separation using DBD plasma actuators on airfoils: a tool for more efficient wind turbine operation," Renewable Energy, vol. 42, pp. 105-110, 2012.

[16] T. Jukes, T. Segawa, S. Walker, H. Furutani, N. Iki, and S. Takekawa, "Active separation control over a NACA0024 by DBD plasma actuator and FBG sensor," Journal of Fluid Science and Technology, vol. 7, no. 1, pp. 39-52, 2012.

[17] M. Sato, H. Aono, A. Yakeno et al., "Multifactorial effects of operating conditions of dielectric-barrier-discharge plasma actuator on laminar-separated-flow control," AIAA Journal, vol. 53, no. 9, pp. 2544-2559, 2015.

[18] T. Segawa, J. Pang, T. Ikehara, R. Maeda, and H. Yoshida, "MEMS based cantilever sensor for fluid dynamics measurements," in MEMS and Related Material Technologies, pp. 217243, Research Signpost, Kerala, India, 2010.

[19] T. Segawa, T. Jukes, Y. Yuki et al., "Feedback control of flow separation on NACA0024 airfoil under periodic wall oscillation by means of DBD plasma actuator and FBG sensor," in Proceedings of the 51st AIAA Aerospace Sciences Meeting including the New Horizons Forum and Aerospace Exposition, AIAA Paper, no. 2013-1115, Grapevine, Tex, USA, 2013.

[20] T. N. Jukes, T. Segawa, and H. Furutani, "Flow control on a NACA 4418 using dielectric-barrier-discharge vortex generators," AIAA Journal, vol. 51, no. 2, pp. 452-464, 2013.

[21] D. E. Ashpis, M. C. Laun, and E. L. Griebeler, "Progress toward accurate measurements of power consumptions of DBD plasma actuators," in Proceedings of the 50th AIAA Aerospace Sciences Meeting including the New Horizons Forum and Aerospace Exposition, AIAA Paper no. 2012-0823, May 2012.

[22] Y. J. Rao, "Recent progress in applications of in-fibre Bragg grating sensors," Optics and Lasers in Engineering, vol. 31, no. 4, pp. 297-324, 1999.
[23] T. N. Jukes, "Smart control of a horizontal axis wind turbine using dielectric barrier discharge plasma actuators," Renewable Energy, vol. 80, pp. 644-654, 2015. 


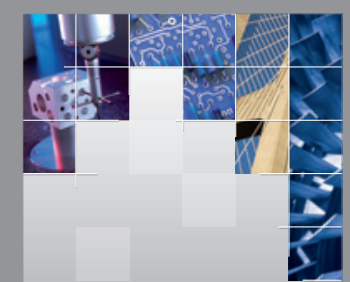

\section{Enfincering}
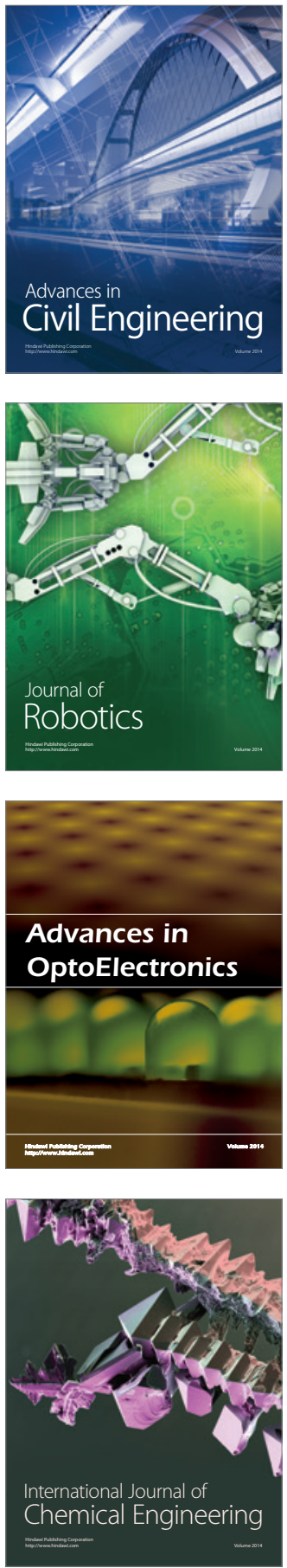

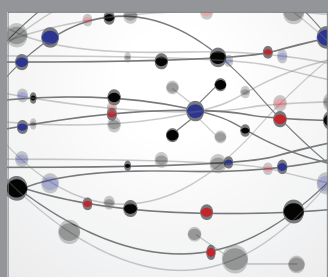

The Scientific World Journal

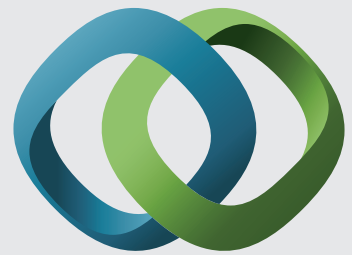

\section{Hindawi}

Submit your manuscripts at

http://www.hindawi.com
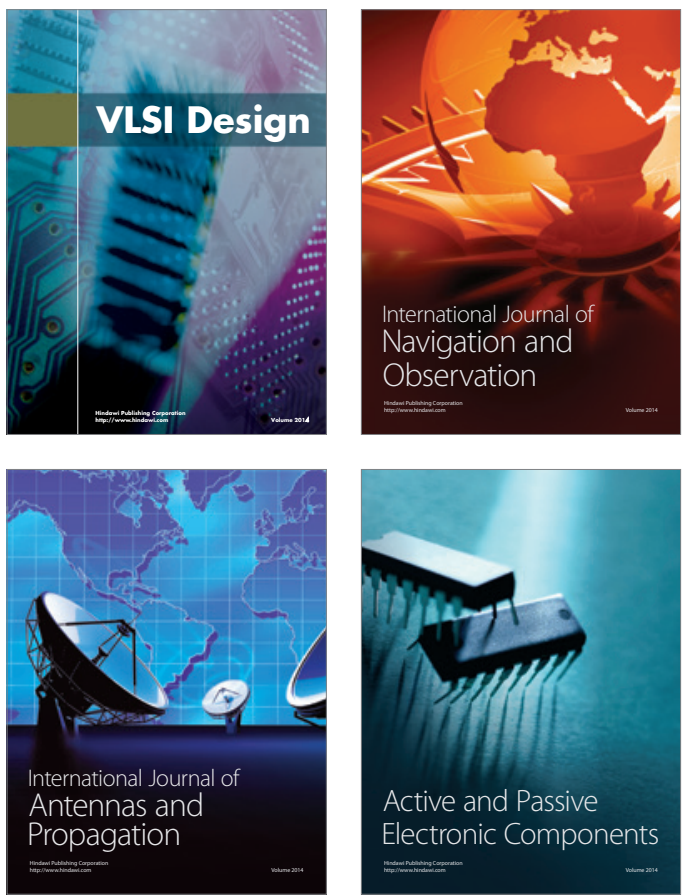
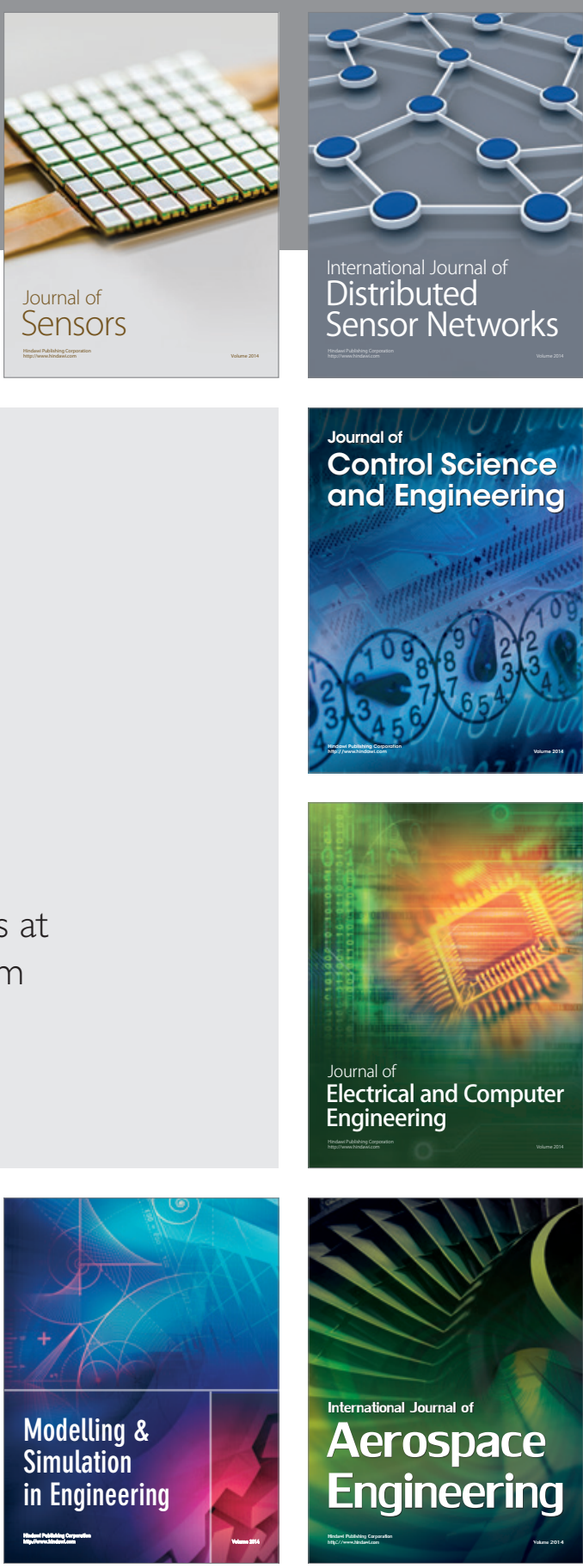

International Journal of

Distributed

Sensor Networks

Journal of

Control Science

and Engineering
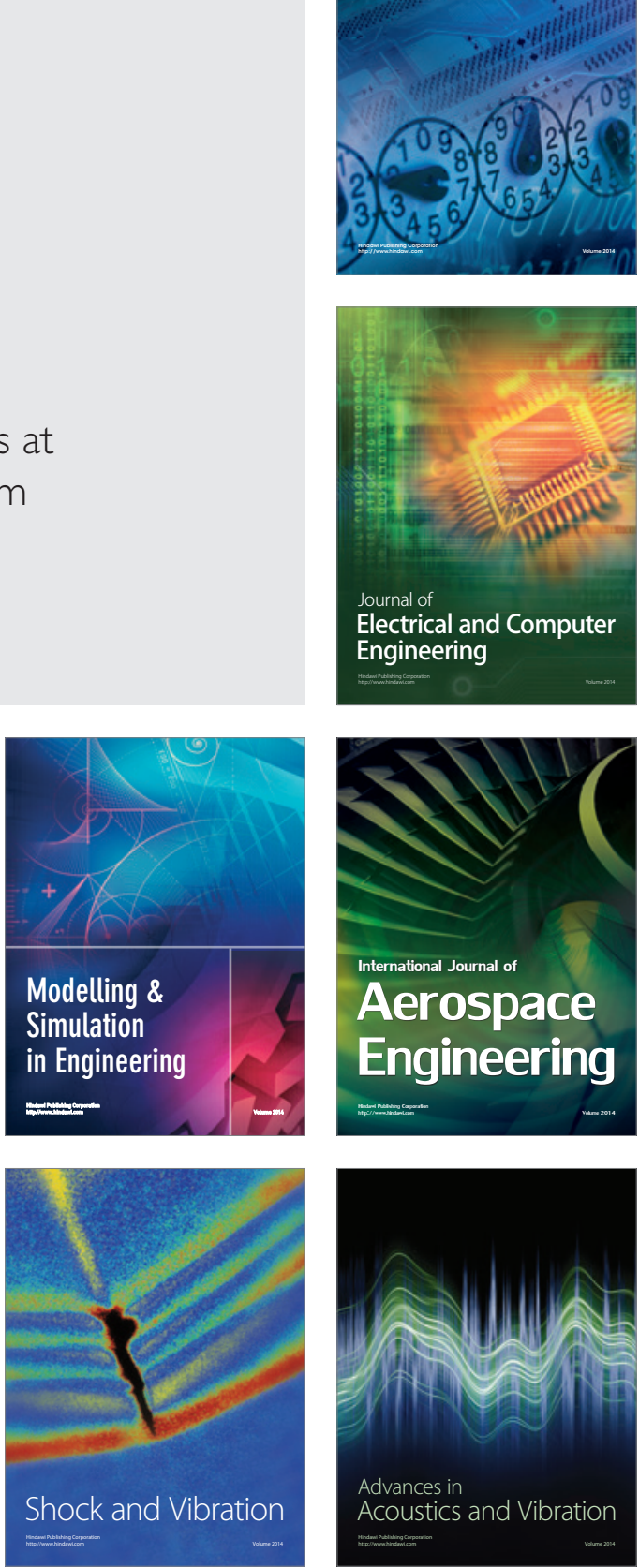